\title{
Dynamic Construction of a Neural Network from Multiple Pattern Generators in the Lobster Stomatogastric Nervous System
}

\author{
Pierre Meyrand, John Simmers, and Maurice Moulins \\ Laboratoire de Neurobiologie et Physiologie Comparées, Université de Bordeaux I and CNRS, 33120 Arcachon, France
}

In the stomatogastric nervous system (STNS) of the lobster Homarus gammarus, the rhythmic discharge of a pair of identified modulatory neurons (PS cells) is able to construct de novo a functional network from neurons otherwise belonging to other functional networks. The PS interneurons are electrically coupled and possess endogenous oscillatory properties that can be activated synaptically by stimulation of an identified sensory pathway. PS neurons themselves project synaptically onto the three major neural networks (esophageal, gastric mill, and pyloric) of the STNS. When a PS is rhythmically active in vitro, either spontaneously (rarely) or in response to direct stimulation, it dramatically restructures the otherwise independent activity patterns of all three target networks. This functional reconfiguration elicited by a single cell does not rely on changes in neuronal allegiance to preexisting circuits, or on a simple merger of these different circuits. Rather, PS is responsible for the creation of an entirely new motor rhythm in that, via its widespread synaptic connections, the interneuron is able to subjugate the ongoing activity of the three STNS circuits and selectively appropriate individual elements to its own intrinsic rhythm. In addition, PS excites motor neurons that innervate dilator muscles of a valve situated between the esophagus and the stomach. The reorganization of the regional foregut motor rhythms by the interneuron is therefore coordinated to the opening of this valve, which itself carries sensory receptors that have been found to activate bursting in PS. Our data suggest that the role of PS in massively restructuring stomatogastric output is to generate a unique motor pattern appropriate for swallowing-like behavior. In a wider context, moreover, the results demonstrate that a neural network may not exist as a predefined entity within the CNS, but may be dynamically assembled according to changing behavioral circumstances.

[Key words: Crustacea, stomatogastric nervous system, neural networks, modulatory interneuron, bursting properties, network reconfiguration, swallowing behavior]

The CNS can be considered as an ensemble of neuronal networks, subsystems of interconnected neurons that are each dedicated to a particular function. One type of neural circuit are those responsible for rhythmic motor behaviors, so-called cen-

\footnotetext{
Received Mar. 26, 1993; revised July 8, 1993; accepted July 15, 1993.

This work was supported by the Human Frontier Science Program.

Correspondence should be addressed to Dr. Pierre Meyrand, Laboratoire de Neurobiologie et Physiologie Comparées, Université de Bordeaux I and CNRS, Place du Dr. Peyneau, 33120 Arcachon, France.

Copyright (C) 1994 Society for Neuroscience $0270-6474 / 94 / 140630-15 \$ 05.00 / 0$
}

tral pattern generators (CPGs) because of their intrinsic ability to produce elemental output patterns in the absence of sensory input (Delcomyn, 1980). In a number of preparations, especially of simpler invertebrates (Getting, 1989), the cellular and synaptic properties underlying this endogenous rhythmicity have been investigated, and are now relatively well understood. It is also now clear that in vivo, individual CPGs do not have a fixed output but can assume different functional configurations and produce a variety of motor patterns according to sensory (e.g., Getting and Dekin, 1985; Bekoff et al., 1987; Katz and HarrisWarrick, 1991) and central modulatory inputs (Harris-Warrick et al., 1992). While reinforcing the notion of the "polymorphic" neural network (Getting, 1989), however, these studies have remained within the conceptual framework of individual CPGs operating as more-or-less discrete entities, each responsible for the elaboration of a specific, albeit flexible, motor behavior.

Recently, however, attention has become focused on a number of indications that central pattern-generating networks do not always operate as structurally and functionally independent units, but can interact to produce complex and behaviorally different changes in motor output. In vertebrates, for example, different coordinations of "unit" CPG circuits (Grillner, 1981) can produce behaviors as diverse as walking, running, swimming, and scratching (Grillner, 1985). In the lamprey spinal cord, changes in coordination of segmental rhythm generating circuits can produce undulatory movements appropriate for forward or backward swimming (Grillner, 1991), while in Tritonia, different combinations of interacting neurons result in swimming or a defensive withdrawal rcsponsc (Getting and Dckin, 1985). What neural processes underlie the network reorganization required for this level of behavioral flexibility?

In this respect, insight has been gained by recent cellular studies on the stomatogastric nervous system (STNS) of Crustacea. Although the four major rhythm-generating circuits of the STNS have been considered classically as separate functional entities on the basis of their different neuronal composition, activity patterns, and the different muscle assemblages they control (Selverston and Moulins, 1987), it is now evident that these circuits interact to a greater extent than previously thought. For example, Hooper and Moulins (1989) demonstrated that a single pyloric neuron can switch its firing pattern from the pyloric to cardiac sac networks, while neurons thought to be involved exclusively in the generation of the gastric motor rhythm were found able to participate in pyloric network activity and vice versa (Weimann et al., 1991). In an another recent study, a bath applied peptide was found to elicit a new rhythm in which the cardiac sac and gastric networks were coordinately active (Dickinson et al., 1990). In all three cases, however, the behavioral significance of these internetwork interactions and the cellular 

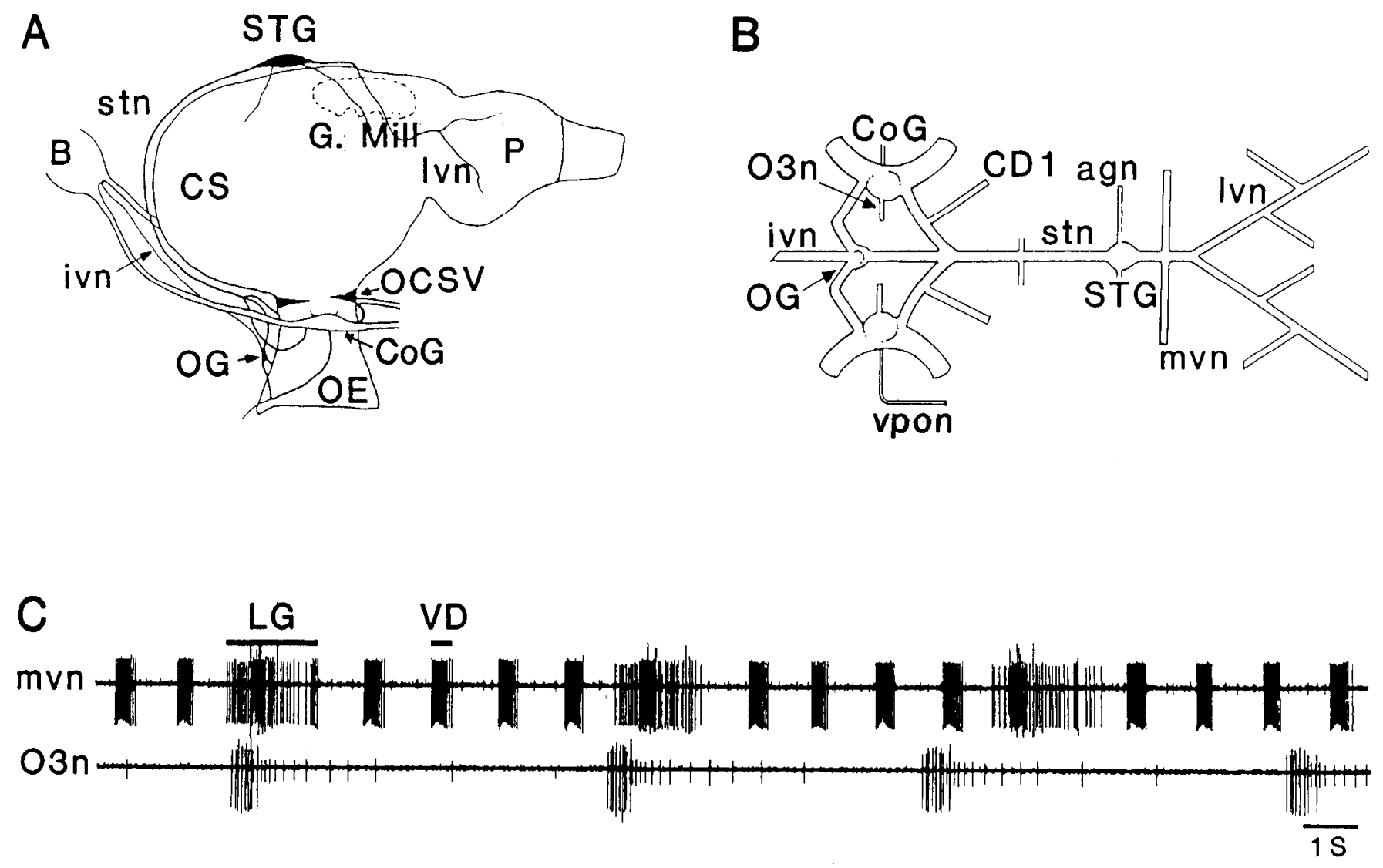

Figure 1. The STNS of the lobster, Homarus gammarus. A, Lateral view of the foregut showing the four different functional regions and the STNS in situ. Anterior is toward the left. $B$, Schematic representation of the STNS after isolation. $C$, Simultaneous extracellular nerve recordings showing typical spontaneous motor output of the different STNS networks in vitro. B, brain; CoG, commissural ganglion; $C S$, cardiac sac; $G$. Mill, gastric mill; $L G$, lateral gastric motor ncuron; $O C S V$, csophagcal cardiac sac valvc; $O E$, csophagus; $O G$, csophagcal ganglion; $O 3 n$, csophagcal nerve 3 containing dilator OD1 (largest unit) and constrictor OC (smallest unit) motor neurons; $P$, pyloric chamber; $S T G$, stomatogastric ganglion; $V D$, ventral dilator motor neuron; agn, anterior gastric nerve; $i v n$, inferior ventricular nerve; $l v n$, lateral ventricular nerve; $m v n$, median ventricular nerve; sth, stomatogastric nerve; vpon, ventral posterior esophageal nerve.

pathways that might govern them in vivo remain unknown. Importantly moreover, in these examples the structural and functional integrity of each original network is essentially maintained. Thus, the possibility that individual neurons are able to participate in behaviors other than those gencrated by preexisting neuronal circuitry was not addressed.

In the present study, we have investigated the global reorganization of lobster stomatogastric networks induced by the rhythmic discharge of a pair of identified interneurons. We find that these neurons, originally located and named "pyloric suppressor" (PS) neurons on the basis of their inhibitory influence on the bursting properties of certain pyloric neurons (Cazalets et al., 1990a,b), are able to reconfigure the different STNS networks into a new functional circuit that bears no resemblance to any of the original networks. This de novo network construction relies on the capacity of PS to override selectively the synaptic and cellular events responsible for the generation of the pyloric, gastric, and esophageal rhythms, and to recombine certain of these elements into a new network that is active in time with interneuron's own endogenous bursting. We have also examined the effects of PS on other STNS motor output, as well as its control by sensory input pathways. Our results lead us to conclude that PS is intimately involved in organizing and driving a hitherto undescribed foregut motor activity, namely, that underlying swallowing-like behavior.
Preliminary reports of some of these data have appeared (Meyrand et al., 1991; Simmers et al., 1991).

\section{Materials and Methods}

All experiments $(n=75)$ were performed on the European lobster, Homarus gammarus, obtained from local fishery supply. The animals, weighing $300-400 \mathrm{gm}$, were maintained in the laboratory in large tanks of aerated circulating seawater at $14^{\circ} \mathrm{C}$.

Electrophysiology. Two types of in vitro preparation were used in electrophysiological experiments reported here.

(1) The completely isolated stomatogastric nervous system (STNS; see Fig. 1) using standard dissection and recording procedures described previously (Selverston and Moulins, 1987). The stomatogastric ganglion (STG), commissural ganglia (CoG), and the proximal part of the inferior ventricular nerve (ivn), which contains the somata of the PS neurons, were desheathed to allow access for intracellular recordings, while the activity of individual nerves was monitored extracellularly with monopolar platinum wire electrodes.

(2) A nervous system-muscle preparation consisting of the STNS left attached to the foregut after the latter had been removed from the animal and opened along the ventral midline. After pinning out on a Sylgardlined petri dish, the PS neurons were recorded intrasomatically in the ivn, while a second microelectrode was used to record from individual fibers of selected foregut muscles.

The physiological saline used to bathe both types of preparation consisted of (in mM) $479 \mathrm{NaCl}, 12.74 \mathrm{KCl}, 13.2 \mathrm{CaCl}_{2}, 10 \mathrm{MgSO}_{4}, 3.9$ $\mathrm{Na}_{2} \mathrm{SO}_{4}, 5$ HEPES, and adjusted to $\mathrm{pH} 7.45$ with $\mathrm{HCl}$ or $\mathrm{NaOH}$. The preparations were continuously superfused with saline held at constant temperature $\left(12-14^{\circ} \mathrm{C}\right)$ with a laboratory-constructed thermoelectric 
A

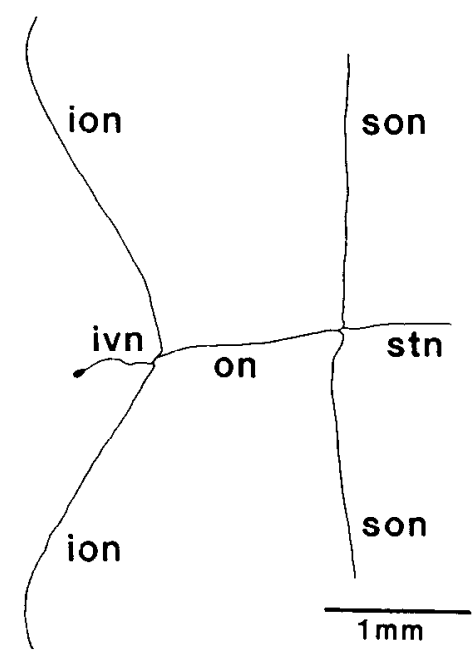

B

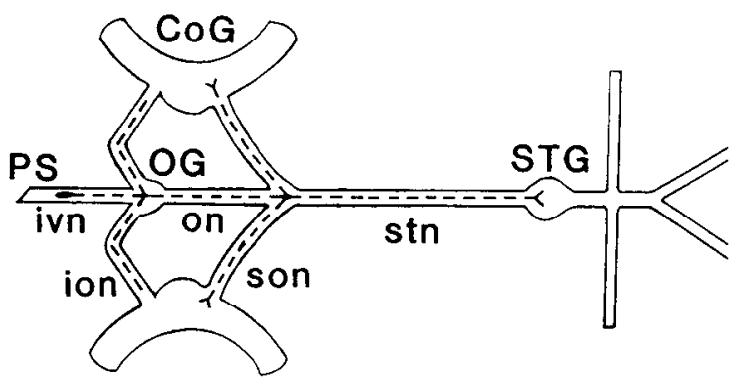

Figure 2. Morphological and electrophysiological identification of the PS neurons. $A$, Camera lucida drawing of one PS neuron after injection of HRP. $B$, Schematic representation of PS in the STNS showing its soma location in the inferior ventricular nerve (ivn), and axonal processes. $C$, Four superimposed oscilloscope sweeps triggered by PS spikes recorded intrasomatically. Each action potential in the soma is followed at constant latency by an extracellular spike in the superior esophageal (son) and stomatogastric (stn) nerves. $D-F$, Each PS spike elicits a constantlatency EPSP in pyloric motor neuron VD in the STG ( $D$, three sweeps), esophageal constrictor motor neuron $O C$ in the $\operatorname{CoG}(E$, six sweeps), and the left and right commissural gastric interneurons ( $C G l, C G r)$ in the CoGs $(F$, four sweeps). ion, inferior esophageal nerve; on, esophageal nerve; son, superior esophageal nerve. See Figure 1 for other abbreviations. Calibration $(C-$ $F): 5 \mathrm{mV}, 10 \mathrm{msec}$.
C
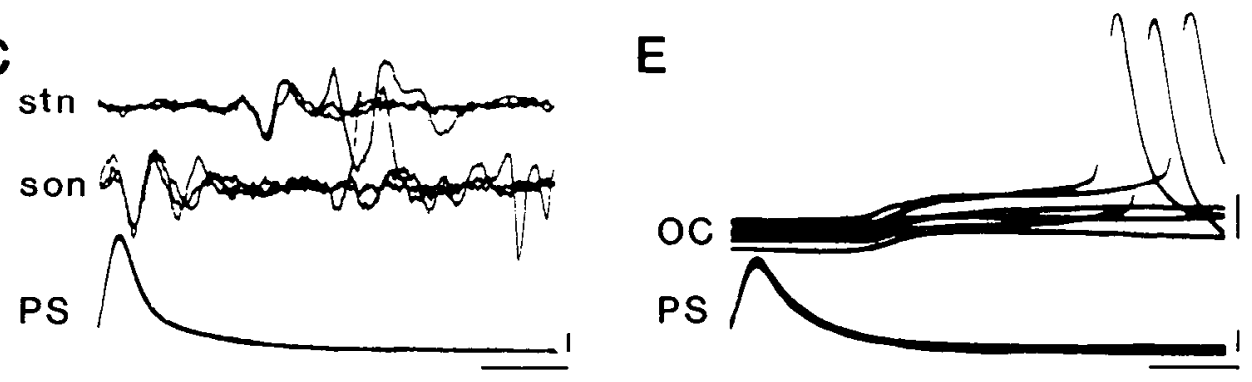

D

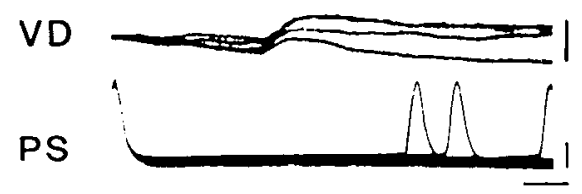

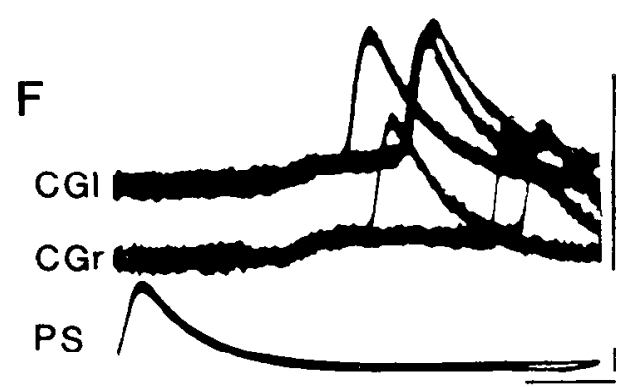

cooling system. Glass micropipettes filled with $3 \mathrm{M} \mathrm{KCl}$ (resistance of 10-20 M $\Omega$ ) were used for both neuron and muscle recordings. World Precision Instruments electrometers were used for intracellular recordings and current injection, while extracellular recordings were made with Grass amplifiers. Signals were displayed on a 5113 Tektronix oscilloscope, stored on an MP 5521 Schlumberger magnetic tape recorder, and transposed on paper with a Gould ES 1000 electrostatic recorder.

In experiments where the PS cell bodies were not impaled with a microelectrode (as in Figs. 7 and $9 B$ ), the interneurons were stimulated extracellularly with a wire electrode placed carefully on the proximal region of the desheathed ivn, between their somata and the esophageal ganglion (see Fig. 2B). As established previously (Cazalets et al., 1990a), the effects of stimulating the ivn in this region derive solely from the activation of the PS neurons since identical stimulation of remaining ivn fibers (by placing the electrode at points more distal to the PS somata) has no effect on STNS activity. Moreover, we verified that all STNS responses to extracellular stimulation of the proximal ivn were seen in other preparations where PS was activated by direct intrasomatic current injection.

Morphology. To visualize the axonal projections of PS, horseradish peroxidase (HRP; $10 \%$ in $0.2 \mathrm{M} \mathrm{KCl}$ ) was injected into one or both PS neurons by applying brief $(250 \mathrm{msec})$ pressure pulses ( $15 \mathrm{psi})$ with a
Picospritzer coupled to the back of an intrasomatically placed microelectrode. Injection times ranged from $30 \mathrm{~min}$ to $1 \mathrm{hr}$, and then the preparation was left for $24 \mathrm{hr}$ at $13^{\circ} \mathrm{C}$ to allow maximum dye migration. The preparation was then exposed to the HRP substrate 3,3'-diaminobenzidine tetrachloride $(1.5 \mathrm{mg} / \mathrm{ml}$; Sigma) to produce a brown reaction product in the injected neuron(s), and standard procedures were subsequently employed to fix, clear, and draw the stained cell in situ under light microscopy. In some experiments, PS somata were injected iontophoretically with $3 \%$ Lucifer yellow $\mathrm{CH}$ (Sigma) and then the neurons were processed and viewed with an epifluorescent microscope, again using conventional methodology.

\section{Results}

Multiple network activity of the STNS in vitro

The foregut of large crustaceans such as lobsters and crabs is divided into two main regions, a short esophagus (Fig. $1 A, \mathrm{OE}$ ) and a large stomach separated by a sphincter, the esophageal cardiac sac valve (OCSV). The stomach itself is divided into three anatomically and functionally distinct compartments; the 
cardiac sac (CS), gastric mill (G. Mill), and pyloric chamber (P) (Fig. 1A). As described originally (Maynard and Dando, 1974), each region is controlled by a specific set of muscles that are innervated by the STNS.

When isolated from the crustacean foregut, the STNS (Fig. $1 B$ ) spontaneously produces the separate rhythmic motor patterns that underlie the different regional behaviors of the foregut in vivo (Fig. 1C; Rezer and Moulins, 1983; Heinzel, 1988). The esophageal rhythm consists of alternating bursts of impulses in the esophageal dilator and constrictor motor neurons occurring at a cycle period of 4-6 sec (Spirito, 1975). The somata of esophageal motor neurons lie either in the esophageal ganglion or the bilateral commissural ganglia (see Fig. $1 B$ ), and their main role is to generate peristaltic movements that move food up the esophageal tract from the mouth toward the cardiac sac region of the stomach (Fig. 1A). In spiny lobsters (Palinurus vulgaris and Panilurus interruptus), motor neurons innervating the cardiac sac region are also involved in a discrete rhythm that operates at cycle periods of between 20 and $60 \mathrm{sec}$ (Moulins and Vedel, 1977; Vedel and Moulins, 1977; Dickinson and Marder, 1989). In our in vitro preparations of the Furopean lobster Homarus gammarus, however, we have never observed cardiac saclike activity either arising spontaneously or in response to neuronal stimulation (see below). Caudal to the cardiac sac is the gastric mill system (Fig. 1A), consisting of two lateral teeth and a single medial tooth that act in combination to shred and chew ingested food (Heinzel, 1988). The period of the gastric rhythm is between 5 and $10 \mathrm{sec}$ and the somata of all gastric motor neurons are located in the STG ganglion (Maynard, 1972). The most caudal region of the foregut consists of the pyloric chamber, which serves to move food from the stomach to the midgut. The movements of the pyloric region are controlled by a welldescribed neuronal network (Miller, 1987) also contained in the STG ganglion and producing the fastest STNS rhythm with a period of 1-2 scc.

In Homarus gammarus, we find patterns of activity and neuronal organization of the networks generating the three main STNS rhythms that are very similar to those described in other species. Figure $1 C$ shows simultaneous extracellular recordings of typical spontaneous activity in pyloric, gastric, and esophageal motor neurons. Here gastric activity was monitored by the lateral gastric motor neuron (LG) recorded from its axon in the medial ventricular nerve (mvn), pyloric rhythmicity by the ventral dilator motor neuron (VD) also carried in the mvn, and esophageal output by esophageal nerve $3(\mathrm{O} 3 \mathrm{n})$, which contains both dilator (OD1) and constrictor (OC) motor neurons.

Although the different STNS circuits underlying these regional foregut activities can generate basal rhythms in the absence of sensory feedback as seen in Figure $1 C$, they are normally subject to an array of modulatory influences that shape motor output to the behavioral needs of the animal. A wide range of ncuroactive substances appear to play a modulatory role within the STNS (Marder, 1987), and several central neurons that modulate these networks have now been identified in various species (Harris-Warrick et al., 1992). Among these identified input neurons is a pair of cells that were previously found in Homarus (Cazalets et al., 1990a) and named pyloric suppressor (PS) on account of their apparent inactivating influence on rhythmic motor output from the pyloric network (Cazalets et al., 1990b). However, as described in the remainder of this report, the PS interneurons not only project onto the pyloric network but also exert dramatic effects on the other STNS networks.

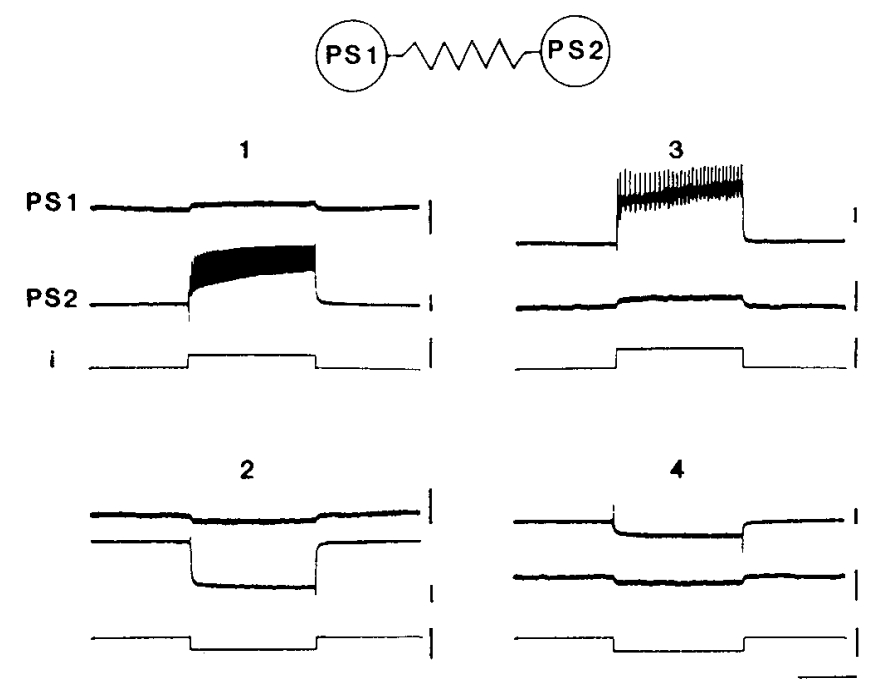

Figure 3. The two PS neurons are electrically coupled. Depolarization (1) or hyperpolarization (2) of one PS (PS2) by current injection (i) causes depolarization or hyperpolarization of its uninjected partner (PS1). Similar responses are obtained in PS2 (3) and (4) by manipulating the membrane potential of PS1. Calibration: $5 \mathrm{mV}$ (current $5 \mathrm{nA}$ ), $1 \mathrm{sec}$.

Location, axonal projections, and endogenous properties of $P S$ cells

In Homarus gammarus, the somata of the two PS interneurons are contained in the ivn, which directly connects the brain to the STNS (Fig. $2 A, B$ ), located side by side within $5-10 \mathrm{~mm}$ of the ivn's point of entry into the esophageal ganglion. Morphological and electrophysiological approaches reveal a complex axonal geometry of the PS cells. First, direct intrasomatic injection of HRP demonstrates that both PS neurons send branches into the five main rostral nerves of the STNS, confirming the earlier observations of Cazalets et al. (1990a), who used cobalt backfills of whole nerve tracts. A single process arising from the monopolar soma descends in the ivn toward the esophageal ganglion, where it splits into three branches (Fig. $2 A, B$ ). The medial branch reaches the son/stn junction nerves via the esophageal nerve (on), while the other two branches pass laterally into the left and right ions and project toward each commissural ganglion. Important to note is that with either HRP (Fig. 2A) or Lucifer yellow injections (not shown), dendritic ramifications or neuropilar processes of PS were never seen in the OG. From the son/stn junction each PS neuron sends axon branches into both sons and the stn, a geometry that is confirmed electrophysiologically in Figure $2 C$, which shows spontaneous intrasomatic spike activity of a PS neuron recorded along with an extracellular monitor of the stn and the bilateral sons. Each soma spike of PS is followed 1:1 and at constant latency by an axonal impulsc in the son and eventually the stn. By contrast, we have never detected extracellular spikes of PS in the ions, nor is it possible to elicit impulses in the soma with direct ion electrical stimulation (see also Cazalets et al. 1990a), suggesting that the projections of PS in the ions are unable to support action potentials.

As suggested by the morphological and physiological data of Figure 2, $A$ and $C$, the branches of each PS serve to distribute the cell to the different stomatogastric ganglia. The widespread nature of the neuron's synaptic connectivity is illustrated in Figure $2 D-F$, where each intrasomatically recorded action potential in PS is followed at constant latency by an EPSP in a 

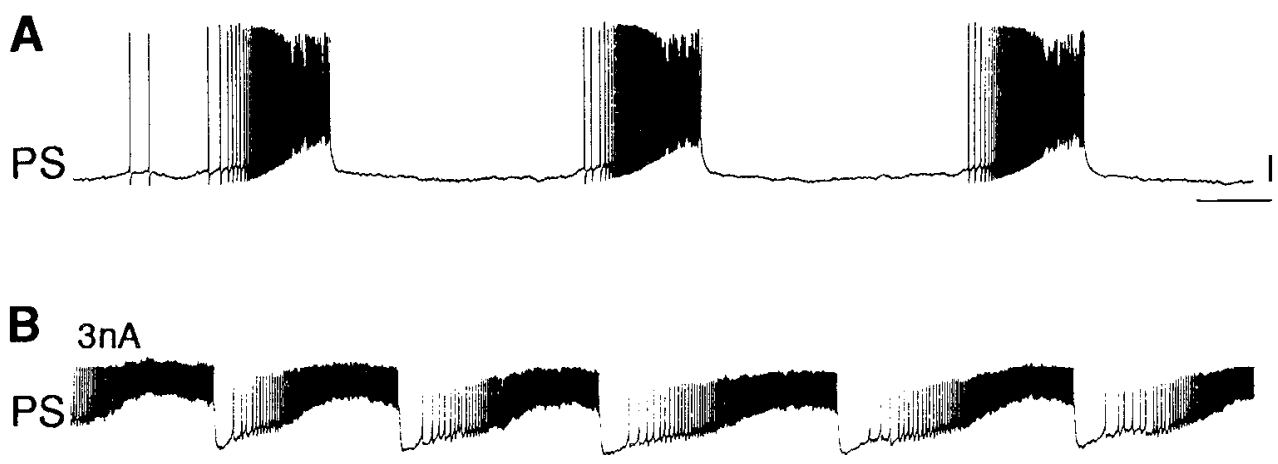

Figure 4. Oscillatory burst-generating membrane property of PS neurons. $A$, Intracellular recording of a PS cell during an episode of spontaneous rhythmic activity. Note the ramp-like depolarization underlying each spike burst and a lack of discrete synaptic activity. $B$, The frequency of oscillation and bursting is voltage dependent. Continuous depolarization of PS with intrasomatic current injection increases the frequency of oscillation as a function of current (1-3 nA). $C$, Resetting of ongoing rhythmic activity in PS (elicited by continuous depolarizing current injection) by a brief $(250 \mathrm{msec})$ hyperpolarizing pulse (2.5 nA) injected into the cell. $A r$ rows above record indicate the expected time of burst termination in the absence of perturbation. Calibration: $10 \mathrm{mV}, 2$ sec.
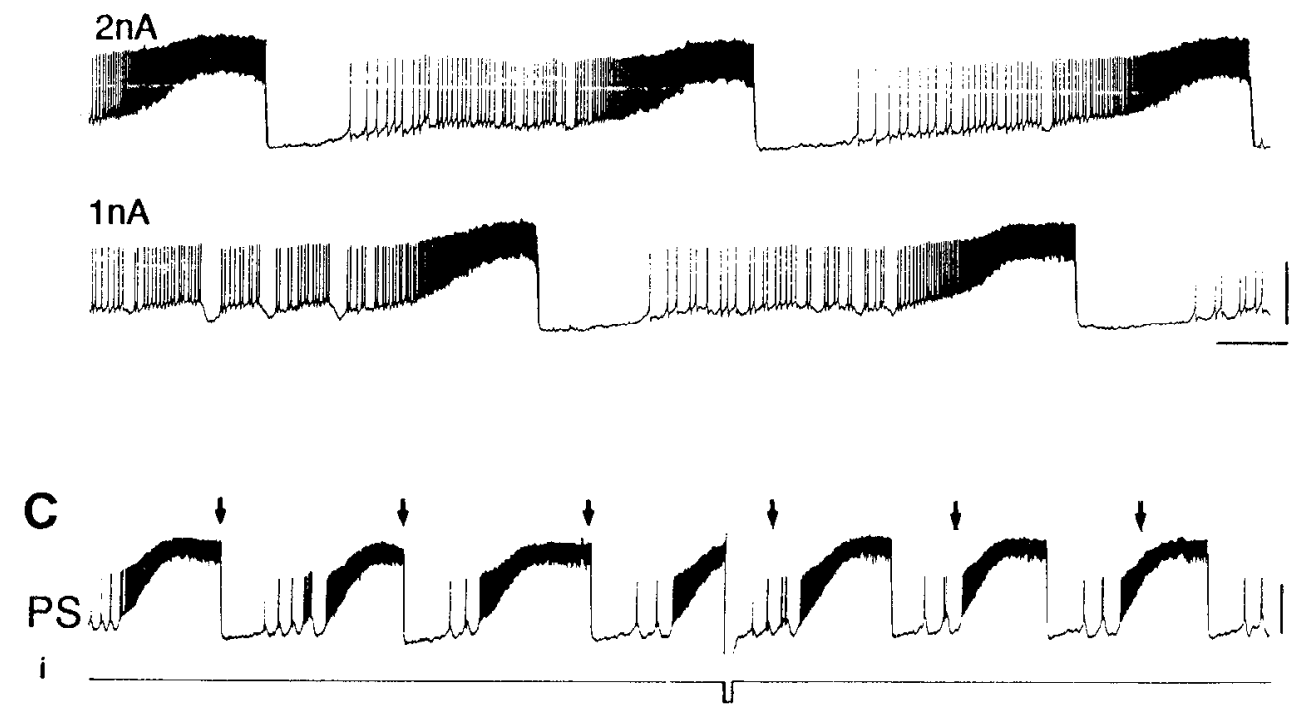

pyloric neuron, the VD located in the STG ganglion (Fig. 2D), an esophageal constrictor motor neuron (OC) in one commissural ganglion (Fig. 2E), and each of the single bilateral pair of commissural gastric interneurons (CG; Simmers and Moulins, 1988) located in the two commissural ganglia (Fig. $2 F$ ). Thus, PS makes output connections in the STG and bilaterally symmetrical connections in the left and right CoGs (Fig. $2 B$ ).

No qualitative differences in axonal geometry and synaptic connectivity of the two PS neurons have been detected, and this apparent equivalence is further indicated by the finding that the two cells are electrically coupled. As evident in Figure 3, where both PS neurons were recorded simultaneously, injection of depolarizing current into the cell body of PS2 (Fig. 3, panel 1) or PS1 (panel 3) caused a depolarization, without delay, of PS1 and PS2, respectively. Conversely, an hyperpolarizing pulse of current injected into either PS2 (Fig. 3, panel 2) or PS1 (panel 4) caused hyperpolarization of the other neuron. The outcome of this electrical coupling, therefore, is that when active the two neurons will tend to operate in synchrony and behave as a functional unit.

Although the PS neurons are generally silent in our in vitro preparations, they very occasionally express bouts of spontaneous rhythmic activity, which consists of oscillations in membrane potential underlying intense bursts of action potentials (Fig. 4A). This rhythmic activity does not appear to arise from a discrete synaptic drive but rather, and as evident in Figure 4, $B$ ande $C$, it appears to be due to an endogenous burst-generating mechanism. First, when PS is silent, the injection of sustained depolarizing current into the soma invariably elicits oscillatory activity (Fig. $4 B$ ) consisting of repetitive ramp-like depolarizations (pacemaker potentials) that drive rhythmic bursting. Second, the frequency of these current-induced oscillations is voltage dependent in that beyond a discrete activation threshold, an increase in the level of tonic depolarization $(1,2,3 \mathrm{nA}$; rig. $4 B$ ) is associated with a corresponding increase in rhythm frequency. Third, and consistent with a further classical test of an endogenous oscillator (Pinsker, 1977), it is possible to reset the rhythmic activity of PS neurons with experimental perturbation. In the recording of Figure $4 C$, for example, where PS was held tonically depolarized to elicit bursting, an additional brief hyperpolarizing pulse delivered during a cycle of PS activity terminated prematurely the corresponding spike burst and permanently reset the cell's ongoing rhythm (see arrows above records in Fig. 4C). From these observations, therefore, we conclude that the oscillatory capability of the PS neurons is an inherent membrane property of the interneurons themselves.

\section{Influence of PS on STNS neural networks}

Given the widespread synaptic connections and endogenous burst-generating properties of PS, an obvious initial question is whether these interneurons are implicated in generating the different motor rhythms of the foregut. However, that this is not the case can be seen in Figure $5 \mathrm{~A}$ (see also Fig. $1 \mathrm{C}$ ), which shows simultaneous intrasomatic recordings from a ventricular dilator (VD) motor neuron of the pyloric network, a constrictor motor neuron (OC) of the esophageal network, and the medial gastric 

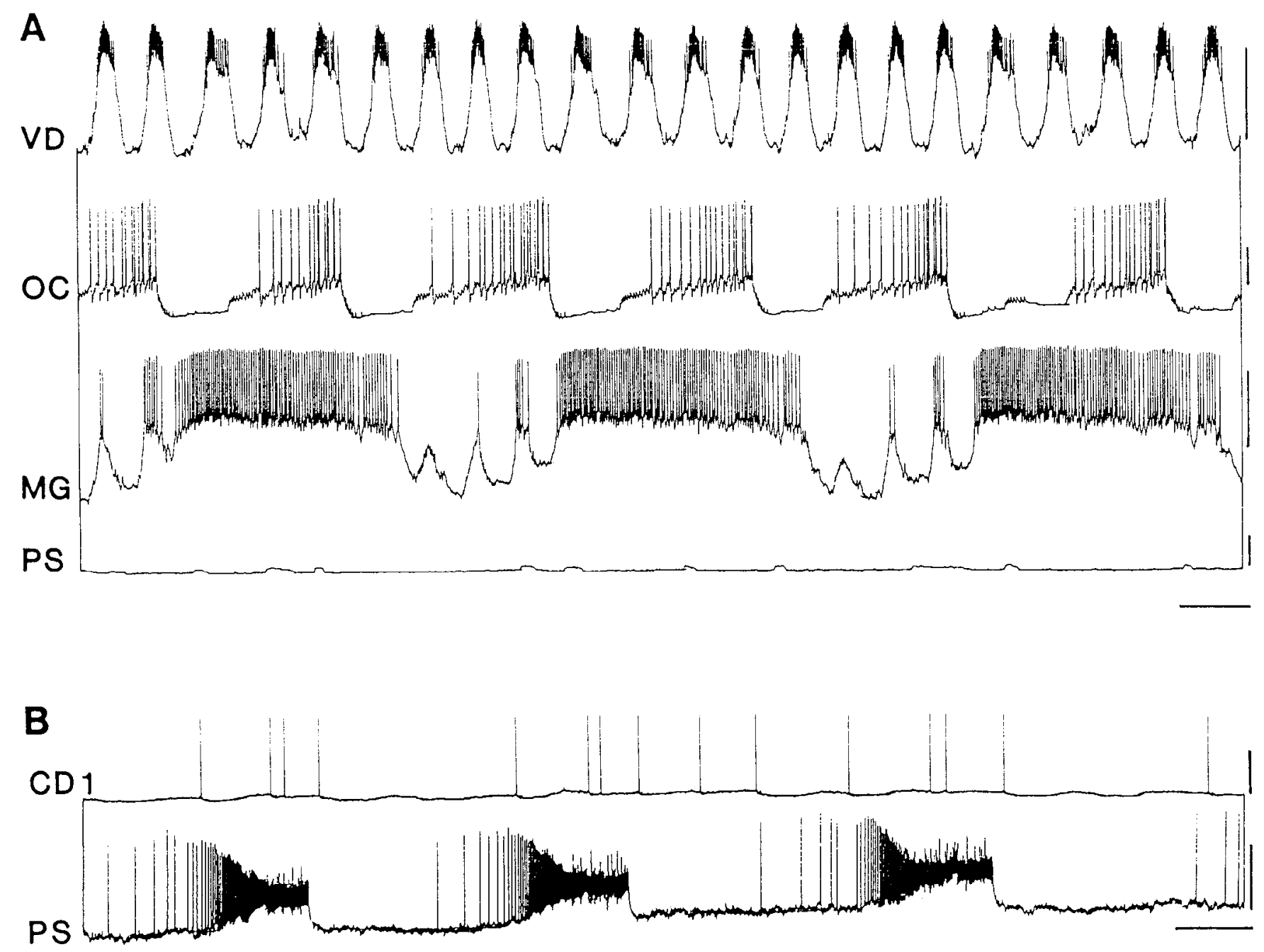

Figure 5. The PS neurons are not necessary for generation of the different STNS motor patterns. $A$, Simultaneous intracellular recordings from pyloric (ventral dilator, $V D$ ), esophageal (esophageal constrictor, $O C$ ), gastric (median gastric, $M G$ ) and PS neurons showing their respective spontaneous output patterns although PS is silent. $B$, PS does not drive the cardiac sac rhythm generation as revealed by an intracellular recording from a cardiac sac neuron (cardiac dilator $1, C D I$ ) during an episode of rhythmic PS firing elicited by tonic depolarizing current. Calibration: 15 $\mathrm{mV}, 2 \mathrm{sec}$.

(MG) motor neuron of the gastric network. In this experiment, a fourth microelectrode monitored $\mathrm{PS}$, which remained inactive throughout the recording sequence illustrated. Evidently, therefore, spontaneous and robust expression of each of these three separate STNS networks has no reliance upon the discharge of interneuron PS.

A second possibility is that the PS neurons act as pacemakers for the cardiac sac rhythm, in a manner homologous to the ivn cells that drive cardiac sac activity in the spiny lobster Palinurus (Moulins and Vedel, 1977). Our inability to observe a distinct cardiac sac rhythm in in vitro preparations of Homarus and the rarity with which PS itself is spontaneously active are consistent with this notion. However, as seen in Figure $5 B$, PS does not appear to be the driver of the cardiac sac rhythm. In this experiment, cardiac dilator motor neuron CDI was monitored intracellularly in the esophageal ganglion while a penetrated PS neuron was held tonically depolarized to elicit rhythmic bursting. Despite intense bursts of discharge in PS, however, CD1 and other cardiac sac motor neurons (not shown) remain weakly active with little evident relationship with the firing of the interneuron.
The synaptic connections of PS with neurons belonging to the pyloric (Cazalets et al., 1990b), gastric, and esophageal networks (Simmers et al., 1991; see also Fig. $2 C-E$ ) suggested that, when active, the interneuron must at least have an influence on the ongoing activities of these three independent networks. To test for such effects we recorded simultaneously from neurons belonging to the different STNS networks when PS was active. In Figure 6, for example, the output of the pyloric and gastric networks was monitored via the axons of VD and $L G$ in the mvn, while the esophageal network was monitored by recording the O3n nerve, which contains the axon of an esophageal dilator motor neuron (OD1). When PS was silent (Fig. 6A; also see Fig. $5 A$ ) these three networks again can be seen to be spontaneously active at characteristic and unrelated cycle frequencies, with the pyloric rhythm (see VD bursts) being the fastest and the gastric rhythm (see LG) the slowest pattern. However, when PS becomes active, as in Figure $6 B$ where bursts were elicited by repetitive depolarization of the cell, a dramatic alteration in these independent motor patterns occurred whereby they now become closely coordinated to the discharge of PS. First, the esophageal dilator neuron in O3n is strongly activated during 


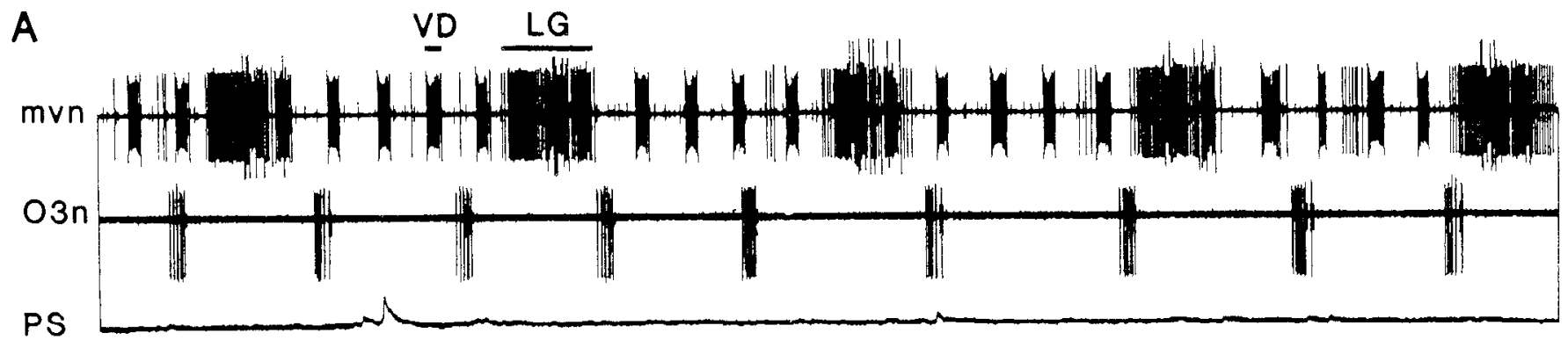

B

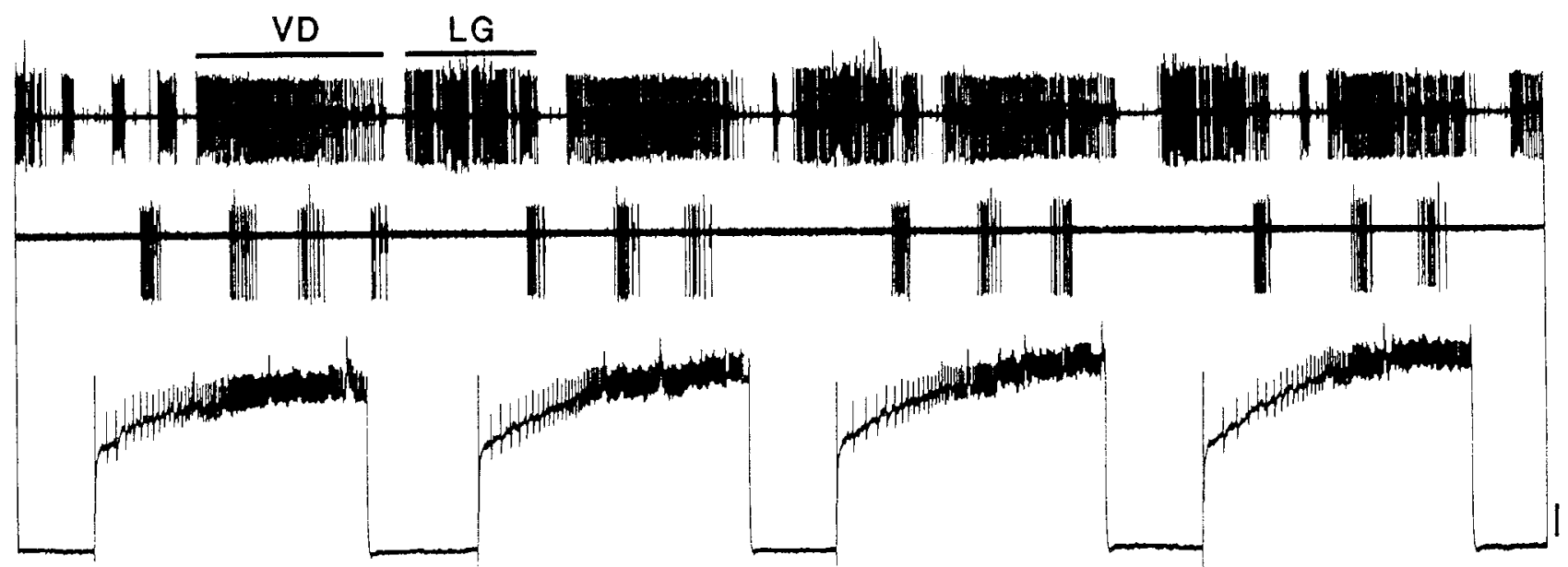

Figure 6. Influence of PS discharge on extracellularly recorded STNS motor patterns. $A$, A PS cell monitored intracellularly along with the pyloric and gastric rhythms recorded extracellularly from the motor nerve (mvn) that contains the axons of pyloric VD and gastric LG neurons, and the esophageal rhythm monitored from the dilator OD1 neuron in the esophageal O3 motor nerve. When PS is silent the three motor networks express their characteristic and independent patterns. $B$. Alteration in these separate patterns during bursts in the same PS elicited by repetitive depolarizing current pulses. Pyloric VD and gastric LG neurons are now coordinated, with VD firing late in the phase of PS discharge and in antiphase with LG. The frequency of the esophageal rhythm is also strongly increased during each PS burst. Calibration: $10 \mathrm{mV}, 2 \mathrm{sec}$.

PS discharge, firing rhythmic multiple bursts in time with each interneuronal burst. Second, the pyloric (VD) and gastric (LG) neurons, which normally operate at completely different periods (Fig. 6A), now burst in strict time with the PS cycle (Fig. 6B), with VD firing prolonged bursts in phase with the discharge of PS while LG is active in antiphase with the interneuron.

These profound changes in STNS network activity during the discharge of PS are further evident in Figure 7, where individual members of the pyloric and gastric circuits were recorded intracellularly. Figure $7 A$ shows the typical independent activity of these networks, here monitored by neurons PD and LPG, respectively, when the PS neurons were silent. However, repetitive high-frequency $(50 \mathrm{~Hz})$ spikc trains (duration of $5 \mathrm{scc}$ ) in PS elicited by direct electrical stimulation of their axons in the ivn (Fig. 7B,C; see Materials and Methods) coordinate the two elements into a single rhythm that is completely unrecognizable from either the original pyloric or gastric rhythms, but which is again coupled to the discharge of PS. Motor neuron PD is strongly depolarized at the onset of PS firing and repolarizes immediately when PS falls silent, and although the cell continues to receive pyloric-like rhythmic synaptic excitation in the interval between each PS burst, it remains silent until the interneuron is once again active. Gastric neuron LPG is also powerfully excited during PS discharge, but with a retarded depolarizing response that far outlasts the interneuron's own duty cycle. Therefore, despite these temporal differences in the responses of individual neurons, the first conclusion from these data is that PS is able to completely reorganize ongoing activity of otherwise independent STNS circuits to produce a single conjoint rhythm consisting of elements firing more or less in phase (e.g., VD, Fig. 6; PD, Fig. 7), biphasically (e.g., LPG, Fig. 7) or in antiphase (e.g., LG, Fig. 6) with the interneuron's own discharge pattern. Moreover, the strict dependence of this reorganized pattern on PS activity is evident in Figure 7, $B$ and $C$, where repetitive stimulation of the PS axons was made at two different cycle periods. In both cases (compare Fig. 7, $B$ and $C$ ) the new conjoint pattern remained closely timed to the burst frequency of PS.

Thesc dramatic cffects of PS do not merely consist of an overall appropriation of each STG circuit to the interneuron's own firing pattern, but rather involve selective and very different influences on individual neurons of each circuit. This diversity in the action of PS is illustrated in Figure 8, where motor output from the pyloric network is monitored by two of its integral members, the VD and LP neurons. When the penetrated PS interneuron is inactive or firing at low frequency, the two pyloric elements express similar and coordinated oscillatory behavior typical of pyloric rhythmicity in vitro (Fig. 8, left). However, when PS itself starts to fire rhythmically (here evoked by continuous intrasomatic depolarization), pyloric activity is immediately disrupted with the neuron VD now firing prolonged bursts in phase with each PS burst. In contrast, neuron LP 

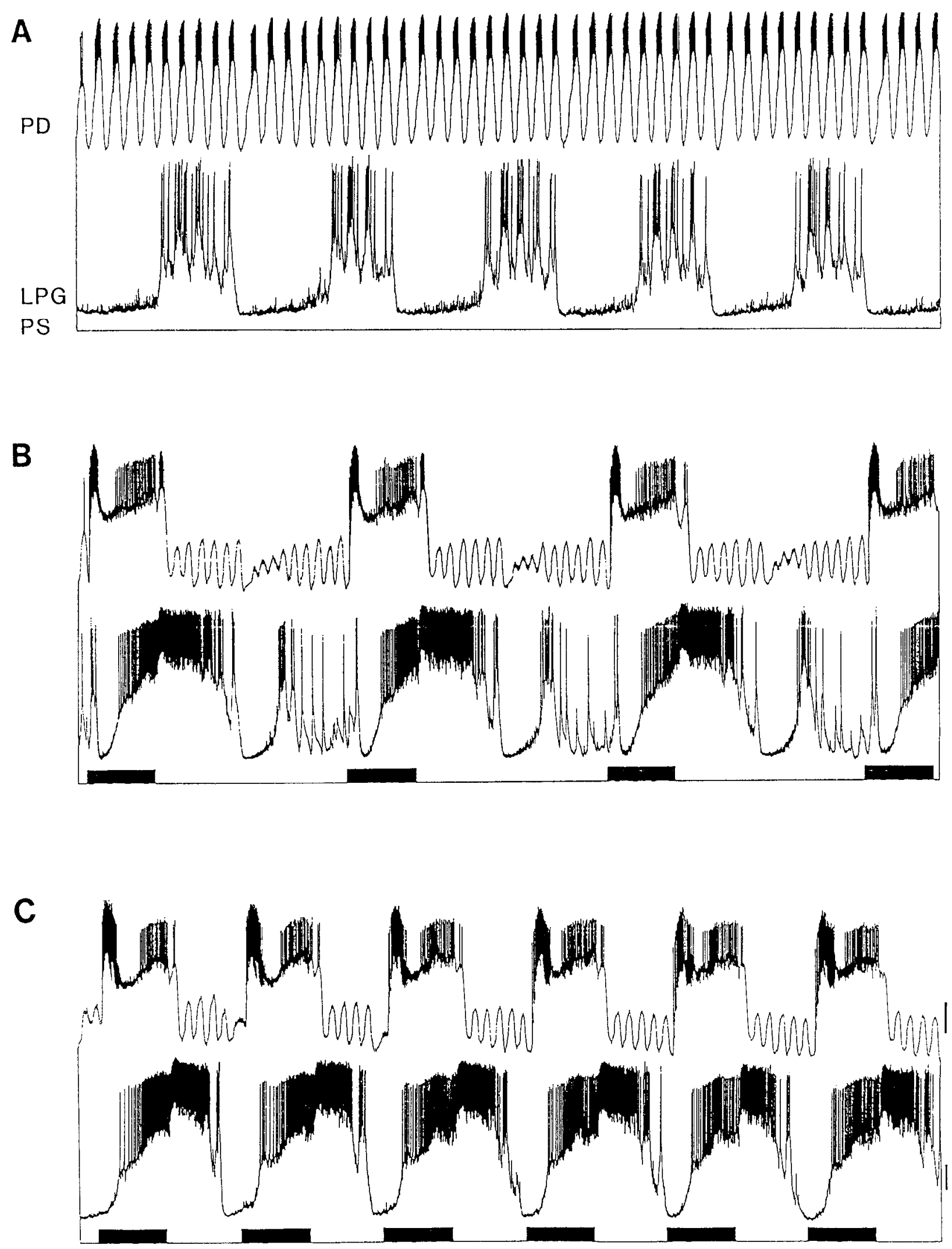

Figure 7. Rhythmic discharge of a PS neuron restructures independent stomatogastric motor outputs into a single pattern timed to the interneuron's own rhythm. $A$, Spontaneous rhythmic activity of the pyloric and gastric networks monitored intracellularly from pyloric $(P D)$ and gastric $(L P G)$ neurons in the absence of PS firing. $B$ and $C$, Repetitive spike trains in PS elicited by extracellular axonal stimulation of the proximal ivn (5 sec trains at $50 \mathrm{~Hz}$; PS traces are direct monitors of stimulation) completely alters the activity of these neurons, which are now coordinated in a single rhythm timed to the firing of PS whatever the stimulus period. The PD neuron is strongly depolarized in phase with PS firing while the LPG neuron receives delayed excitation and continues to fire after each PS burst. Calibration: $10 \mathrm{mV}, 2 \mathrm{sec}$. 


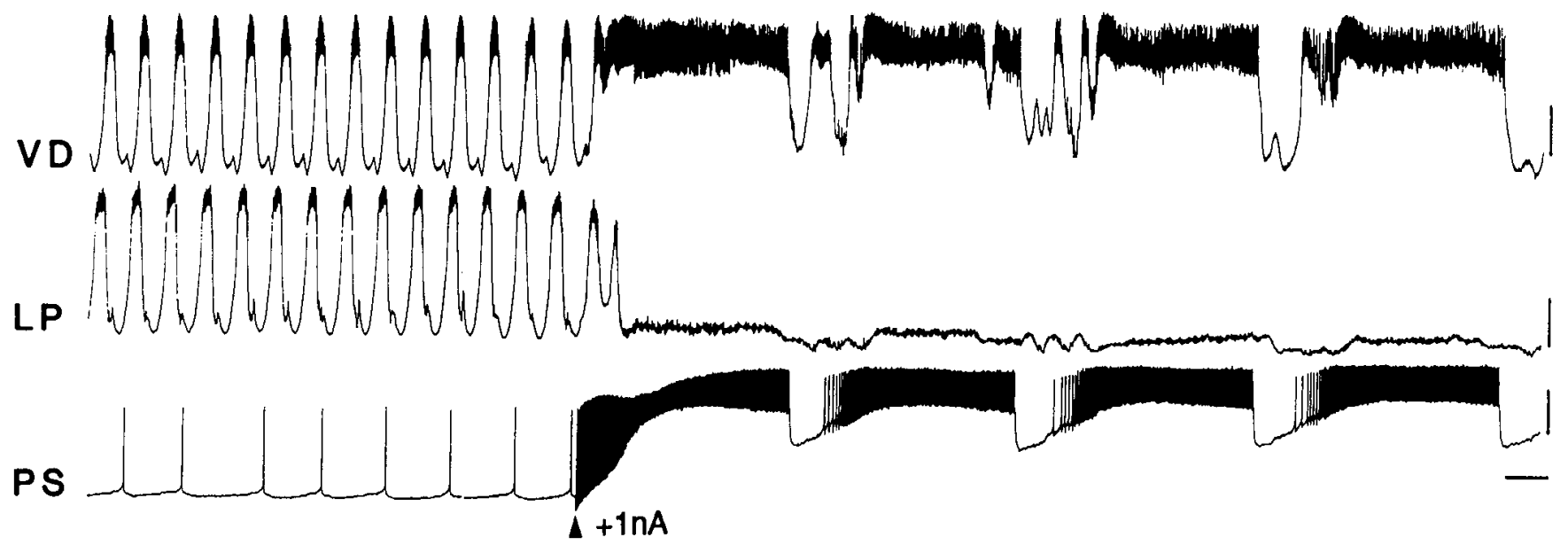

Figure 8. Rhythmic discharge of PS interneuron is able to dismantle the pyloric network. During a spontaneous pyloric rhythmicity (left), here monitored by the VD and LP neurons, PS bursting elicited by tonic intrasomatic current injection (at arrowhead) causes an immediate disruption of the ongoing pyloric pattern; VD is now rhythmically depolarized and fires in phase with PS firing while LP hyperpolarizes and remains completely silent. Calibration: $10 \mathrm{mV}, 1 \mathrm{sec}$.

hyperpolarizes to a relatively steady membrane potential and remains completely inactive throughout the entire episode of PS activity. This demonstrates that PS is not just able to coordinate the activity of elements originating from different STNS networks as seen in Figures 6 and 7, but can functionally dismantle the individual circuits, discarding certain constituent neurons (e.g., LP of the pyloric network in the example of Fig. 8), while recruiting remaining cells (e.g., VD in Fig. 8) to create an entirely new motor pattern.

In addition to these effects seen during PS firing, we also examined whether the interneuron has long-term influences that outlast its own discharge. Following an cpisode of PS firing, the recovery of original STNS network activity occurs in two ways. First, the esophageal network, which controls motor activity of the foregut region rostral to the OCS valve and is strongly activated by PS bursts, returns immediately to original levels of activity when the interneuron falls silent (Fig. $9 A$ ). Second, and in contrast to the esophageal pattern, neurons ordinarily belonging to the gastric and pyloric networks (which control movements of the foregut posterior to the OCS valve) remain coordinated in a single pattern that can persist for some considerable time after the end of an episode of PS activity. As illustrated in Figure $9 B 1$, prior to PS discharge, neurons PD and GM can be seen to participate in the two separate rhythms of the pyloric and gastric networks, respectively. However, after a single 10 sec burst in PS (not shown) these previously independent elements remain coordinated in a single motor pattern (Fig. 9B2) with a cycle period that is different from either the original pyloric or gastric patterns (compare with Fig. 9B1). This unified pattern (in which the PD neuron is unable to express its faster intrinsic pyloric period) persists for several tens of seconds, and as seen in Figure 9B3, the recovery of totally independent pyloric and gastric network activity was still not complete some 3-4 min after the discharge of PS.

\section{PS neurons drive dilation of the esophageal-cardiac sac valve}

In addition to restructuring rhythmic movements normally driven by the three STNS circuits as described above, PS also influences other foregut muscles that are not directly controlled by these networks. Examination of STNS-muscle preparations (see Materials and Methods) revealed that one such set of mus- cles is that controlling the valve situated between the esophagus and the cardiac sac (Fig. 1A). The anatomy of the OCS valve and its associated muscles in Homarus gammarus (Fig. 10A1,2) were previously reported by Robertson and Laverack (1979), who described three extrinsic dilator muscles (OCSV1-3) that open the valve, while contraction of the single intrinsic constrictor muscle (OCSVC) causes the valve to close. The motor neurons that innervate these muscles originate in the commissural ganglia.

In SINS preparations with the anterior part of the foregut left attached, simultaneous intracellular recordings from a PS ncuron and muscle fibers of the OCS valve (Fig. 10B) show that when the interneuron is inactive, motor neurons to the dilator (OCSV3a) muscle remain silent while constrictor motor neurons are spontaneously active, as evident from the continuous barrage of excitatory junction potentials in the OCSVC muscle. Under these conditions, therefore, the OCS valve remains closed, despite ongoing esophageal, gastric, and pyloric rhythmicity (not shown). However, when PS becomes active (Fig. 10B) the dilator motor neurons are now excited, constrictor motor activity ceases, and the valve opens until shortly after the interneuron again falls silent. Moreover, when PS fires rhythmically, whether spontaneously or in response to tonic depolarization (Fig. 10C), the OCSV3a muscle (and hence valve dilation) is driven cyclically in time with the interneuron's own spike bursts, again for as long as the latter remains active.

Although the PS interneurons appear to be intimately involved in driving OCS valve dilation as wcll as causing a massive restructuring of other STNS motor rhythmicity, the cells are very rarely spontaneously active in our in vitro preparations. We were therefore interested in whether PS themselves are subject to synaptic input that might govern their endogenous bursting capability in vivo. One discrete afferent pathway found to influence PS is that shown previously to arise from a bilateral set of sensory neurons (posterior esophageal sensors, pos), presumed chemoreceptors, located on the internal wall of the OCS valve and which send their axons to the commissural ganglia via the left and right ventral posterior nerves (vpons) (Robertson and Laverack, 1979) (see Fig. 11A). That these sensory elements have synaptic access to the active membrane properties of PS is indicated in Figure $11 B$, where a brief electrical stimulation 

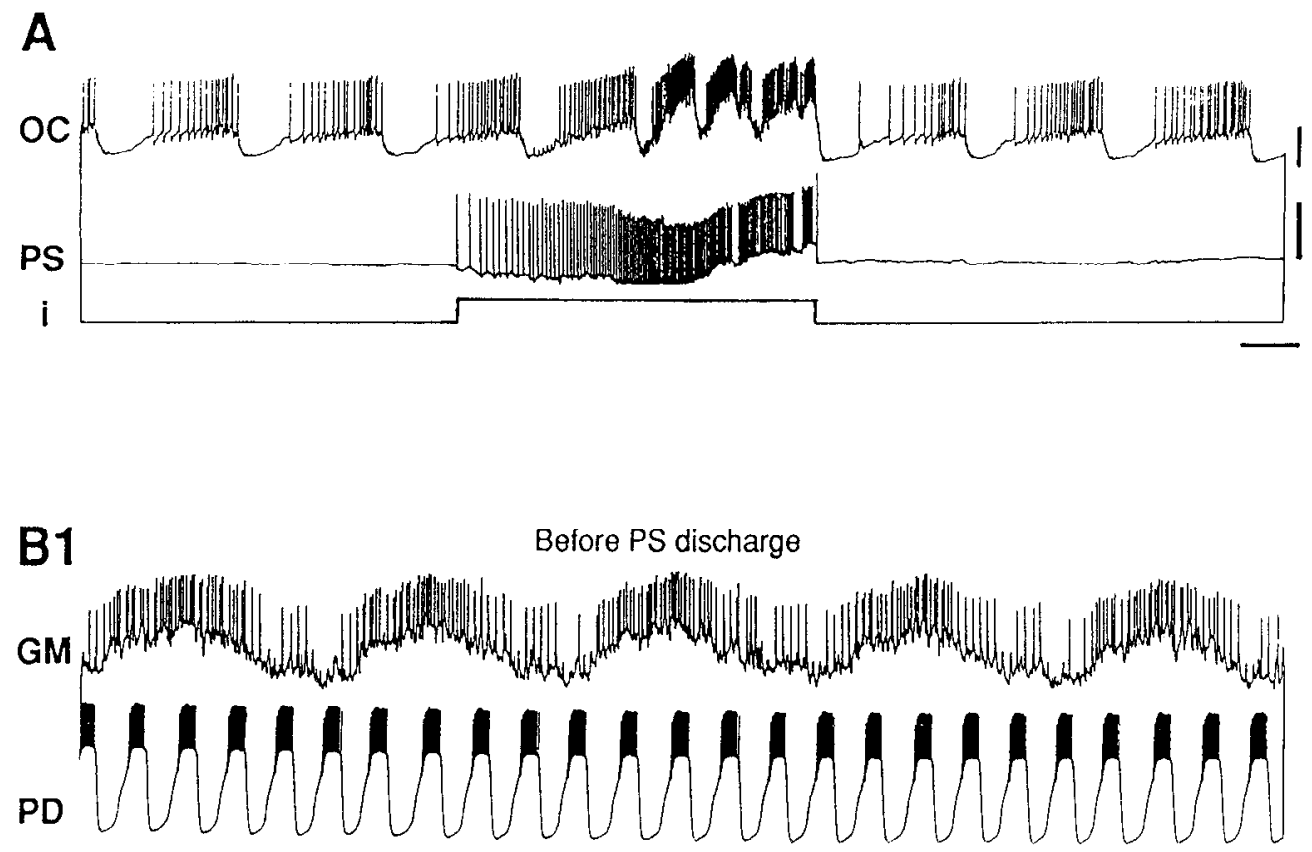

B2

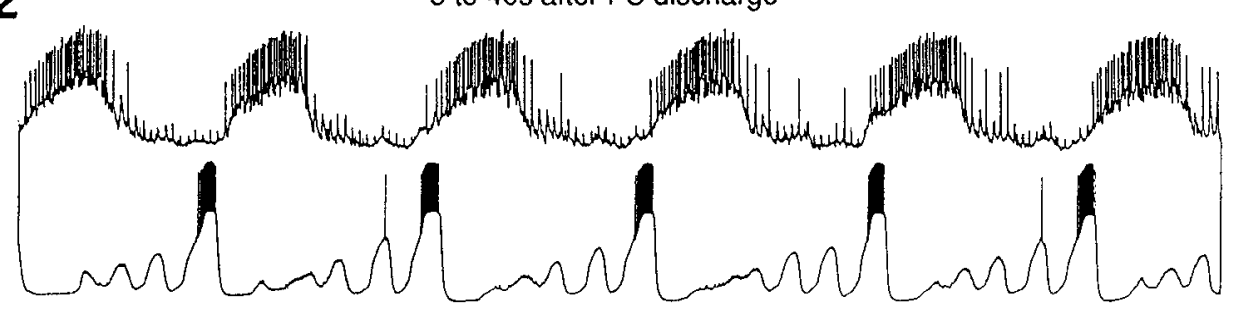

B3

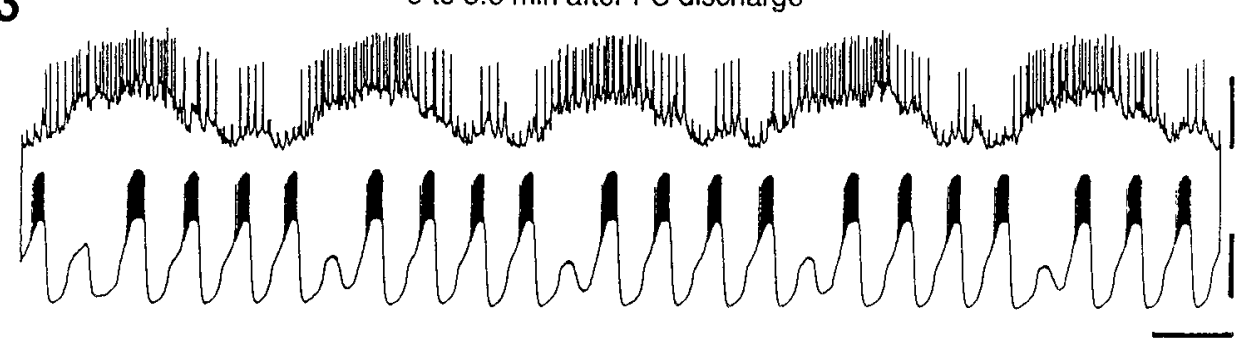

Figure 9. Short- and long-term effects of PS neurons on stomatogastric network activity. $A$, Simultaneous intracellular recordings of an esophageal constrictor neuron $(O C)$ and a PS interneuron. Discharge of PS, elicited by a depolarizing ( $1 \mathrm{nA})$ current pulse (note bridge circuit unbalanced), induces an increase in bursting frequency of $\mathrm{OC}$ but the latter reverts immediately to its initial frequency at the end of PS firing. $B$, Simultaneous recordings from neurons of the gastric $(G M)$ and pyloric $(P D)$ networks before and after PS discharge $(10 \mathrm{sec}$ burst at $25 \mathrm{~Hz}$; not shown). Before PS discharge (BI) the gastric and pyloric networks express two independent output patterns but immediately after PS discharge (elicited by axonal stimulation at $25 \mathrm{~Hz}$ for 10 sec) the same neurons remain coordinated in a single motor pattern $(B 2)$ that gradually weakens but remains evident some 3-4 min later (B3). Calibration: $15 \mathrm{mV}, 2 \mathrm{sec}$.
$(10 \mathrm{msec})$ of either the left or right pos nerve distal to its entry into the corresponding vpon is able to trigger a long-lasting ( 5 sec) "plateau" depolarization in an otherwise silent PS interneuron, during which the cell fires at high frequency. This initial indication that these bilateral sensory pathways may play a physiological role in controlling PS is further substantiated by their ability to initiate and maintain oscillatory bursting activity when stimulated tonically (Fig. 11C). With onset of such stimulation, a previously inactive PS ncuron depolarizes until it reaches threshold for endogenous oscillation and bursting, which is then expressed throughout the period of stimulation (Fig. $11 C$ ). From these observations, we conclude that synaptic excitation mediated by pos axons can activate and sustain the intrinsic bursting capability of PS and, as a consequence, elicit rhythmic dilations of the OSC valve from which they arise.

\section{Discussion}

Our results show that the activity of a pair of electrically coupled modulatory interneurons (PS) can completely reorganize the different neuronal networks of the STNS and using elements of these otherwise independent networks construct a new functional network. We have shown that these interneurons, which appear to be endogenous oscillators, also drive motor output to a small set of foregut muscles not directly implicated in the activity patterns of these other STNS circuits. Moreover, the interneurons can be activated by electrical stimulation of axons 
A 1

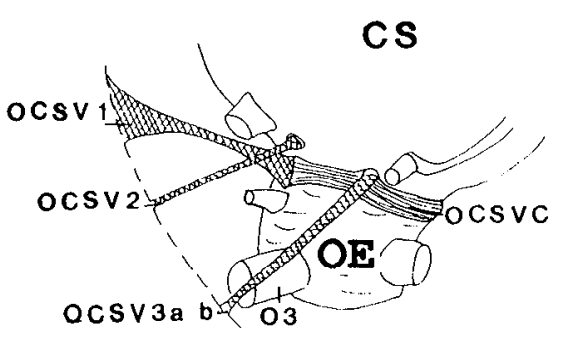

A2

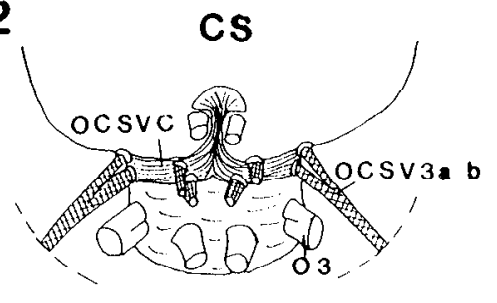

B

Figure 10. The PS neurons control the dilation of the OCS valve between the esophagus and cardiac sac. $A$, Illustration of the OCS valve and muscles. $A 1$, Left lateral view. $A 2$, Frontal view. $B$, Simultaneous intracellular recordings of constrictor $(O C S V C)$ and dilator $(O C S V 3 a)$ muscle fibers of the OCS valve and a PS neuron. Depolarization of PS by current injection $(i)$ causes a depolarization of the dilator fiber $(O C S V 3 a)$ due to a summation of excitatory junction potentials and inhibition of spontaneous tonic firing in motor neurons to the constrictor muscle $(O C S V C)$. $C$, Rhythmic bursting of PS (elicited by current injection) drives phase-locked depolarizations in the dilator muscle of the OCS valve. $C S$, cardiac sac; $O 3$, esophageal dilator muscle 3; $O C S V I-3$, esophageal cardiac sac valve dilator muscles $1-3$; OCSVC, esophageal cardiac sac valve constrictor muscle; $O E$, esophagus. Calibration $(B$ and $C): 10 \mathrm{mV}, 1 \mathrm{sec}$.

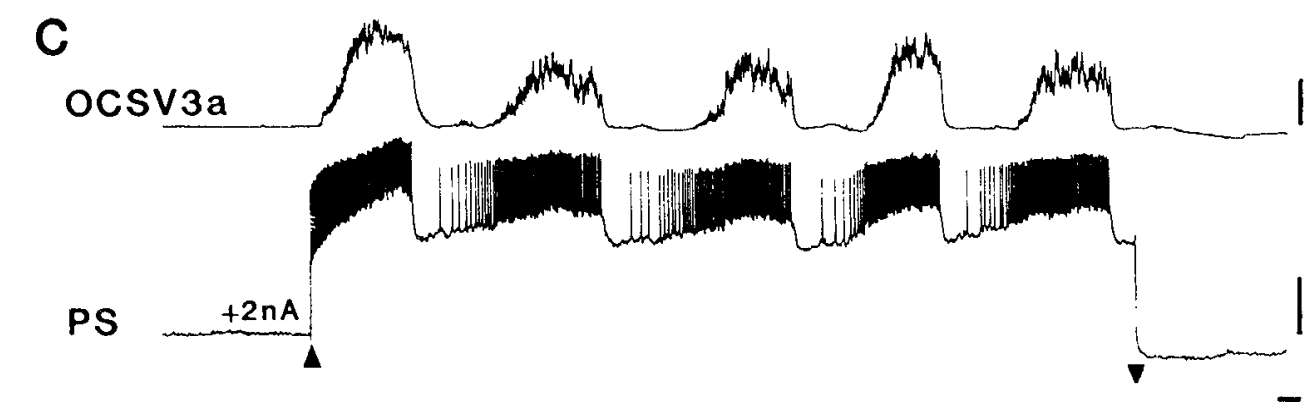

from a previously identified group of chemosensors located in the internal esophageal wall. The reorganizing influence of PS on the different STNS networks and its possible behavioral consequences are summarized in Figure 12.

\section{Swallowing-like activity in lobster}

Although we do not know how the PS interneurons behave in the intact animal, our in vitro data lead us to predict that these two neurons control swallowing-like behavior. When PS is active, its rhythmic bursting drives motor output for opening the OCS valve (Fig. 10) and concomitantly reorganizes all other foregut motor activity so that it becomes coordinated with these movements (Figs. 6-8, 12). During opening of the valve, PS strongly increases the frequency of the esophageal rhythm (Fig. $6 B$ ) and causes intense bursting, especially in esophageal constrictor motor neurons (Fig. 9A). The functional consequence of this effect in vivo is that it serves as the primary act in food transit whereby particles are pushed through the now open valve from the esophagus to the stomach. At this time, the neural networks controlling foregut regions that are posterior to the OCS valve are also altered by the discharge of PS in a manner that would facilitate the rearward passage of food. For example, the pylorus is dilated in phase with each valve opening via the strong activation of dilator motor neurons (e.g., VD in Figs. $6 B$, 8 ) and the complete suppression of activity by the LP constrictor motor neuron. In addition, masticatory movements of the three gastric mill teeth in the stomach cavity are reorganized so that power-stroke movements are either inhibited completely (Meyrand et al., 1991) or timed to occur in phase opposition with each valve dilation (e.g., LG in Fig. $6 B$ ). The functional significance of the coordinated gastropyloric activity that is seen to follow PS discharge (Fig. 9B) is less easy to predict, although presumably this serves in a final mixing process before the gastric and pyloric circuits reassume their separate regional behaviors.

\section{Sensory activation of feeding-related behavior}

In Homarus gammarus, Robertson and Laverack (1979) first reported a group of sensory cells, the posterior esophageal sensors (pos), located on the internal wall of the OCS valve, and that when subjected to direct application of Mytilus extract in semi-intact preparations, caused a powerful enhancement of 

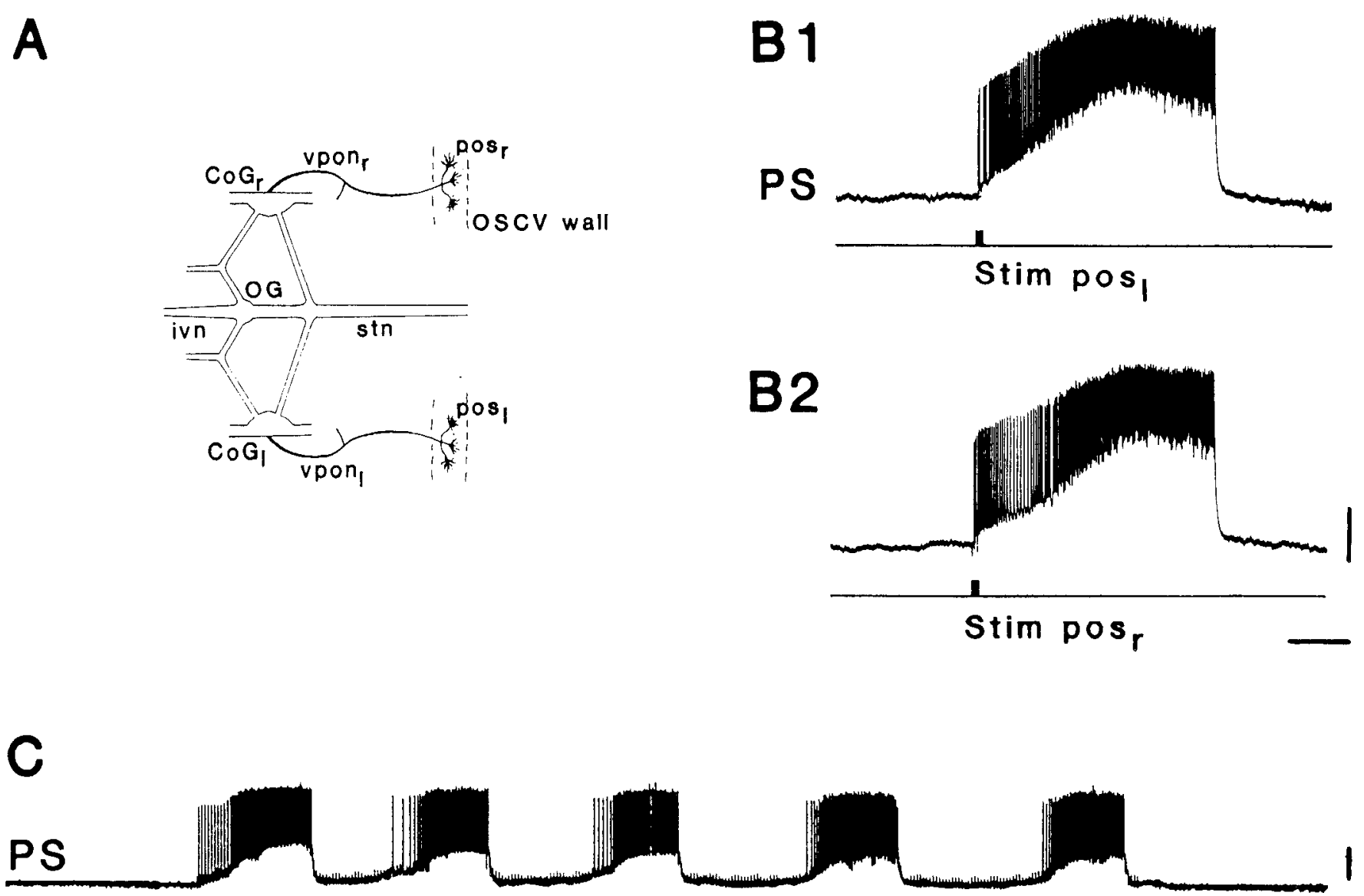

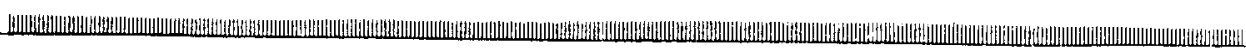

\section{Stim pos $10 \mathrm{~Hz}$}

Figure 11. Sensory activation of PS neurons. A, Schematic representation of the rostral end of the STNS in vitro showing the bilateral nerves $\left(\right.$ vpon $_{i}$ and vpon $_{r}$ ) that carry the axons of the left and right posterior esophageal sensors (pos), chemoreceptors in the internal wall of the OSCV valve, to the corresponding CoG. $B$, A brief electrical stimulation ( $30 \mathrm{~Hz}$ for $250 \mathrm{msec}$ ) of the left $(B 1)$ or right (B2) pos axons triggers a longlasting depolarization in the same PS neuron. $C$, A tonic stimulation $(10 \mathrm{~Hz})$ of the nerve branch from the right pos in a different preparation elicits phasic bursting activity in a PS neuron for the duration of the stimulation. vpon, ventral posterior esophageal nerve. See Figure 1 for other abbreviations. Calibration: $10 \mathrm{mV}, 2$ sec.

esophageal peristalsis. Although the effects of these presumed chemoreceptors on other foregut activity patterns were not investigated in their in vivo experiments, our in vitro data obtained with axonal stimulation of pos suggest that the motor responses observed by Robertson and Laverack (1979) constituted one component of a far more complex behavioral alteration involving all foregut regions and mediated uniquely by the PS interneurons.

Tonic activation from sensory feedback, and especially that arising from chemoreceptors, has been found to play a crucial role in initiating and sustaining feeding-related behaviors in a number of different preparations. In the snail Lymnaea stagnalis, for example, a single interneuron that is able to initiate a feeding rhythm in quiescent isolated preparations (Kemenes et al., 1986) can be activated by chemical stimuli applied to the lips (Rose and Benjamin, 1981a,b). In the carnivorous marine mollusk Pleurobranchea, a population of interneurons are excited by food extracts applied to rhinophores and their discharge also triggers fictive feeding behavior in a previously quiescent preparation (Gillette et al., 1982), while similar observations have been made in Limax (Delaney and Gelperin, 1990a,b) and
Aplysia (Rosen et al., 1991). In vertebrates, moreover, where the act of deglutition is clearly distinguishable from other feeding-related behaviors (Miller, 1982), bouts of swallowing activity can be triggered by the stimulation of discrete sensory fiber tracts running in the superior laryngeal nerve (Jean and Car, 1979). In all these cases, the triggering pathways are assumed to impinge upon discrete neuronal networks that are each dedicated to a particular aspect of overall feeding behavior. This is fundamentally different from the example reported here in that the neurons that appear to satisfy swallowing in lobsters are also involved in other food processing tasks when swallowing is not heing expressed (see below).

\section{Construction of a pattern-generating network with neurons belonging to different networks}

The crustacean STNS has been considered to embody four discrete and essentially independent pattern-generating networks on the basis of their different neuronal composition, activity patterns, and the muscle assemblages they control (Selverston and Moulins, 1987). An important feature of the STNS is that unlike many other systems, motor neurons are themselves in- 
A

PS silent

Oes. Net.

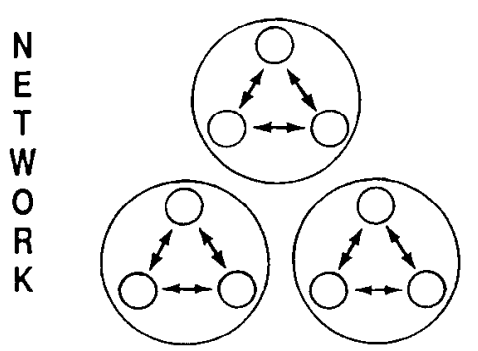

Gastric Net. Pyloric Net.
B

PS active

Swallowing Net.

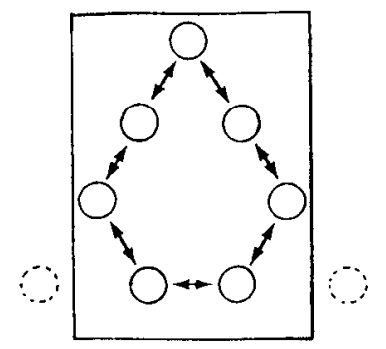

C

Post PS activity

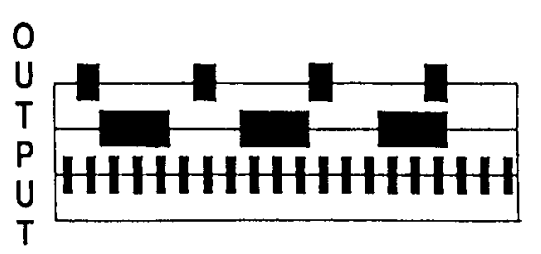

T

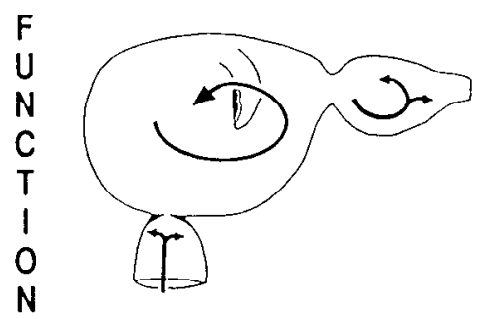

\section{Oes
Gast
Pyl
PS}

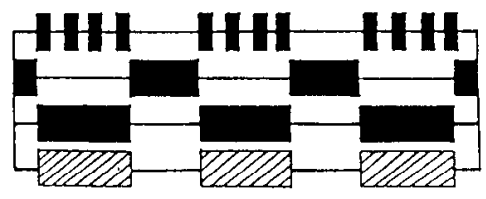

\section{Oes \\ Gast \\ Pyl \\ PS}
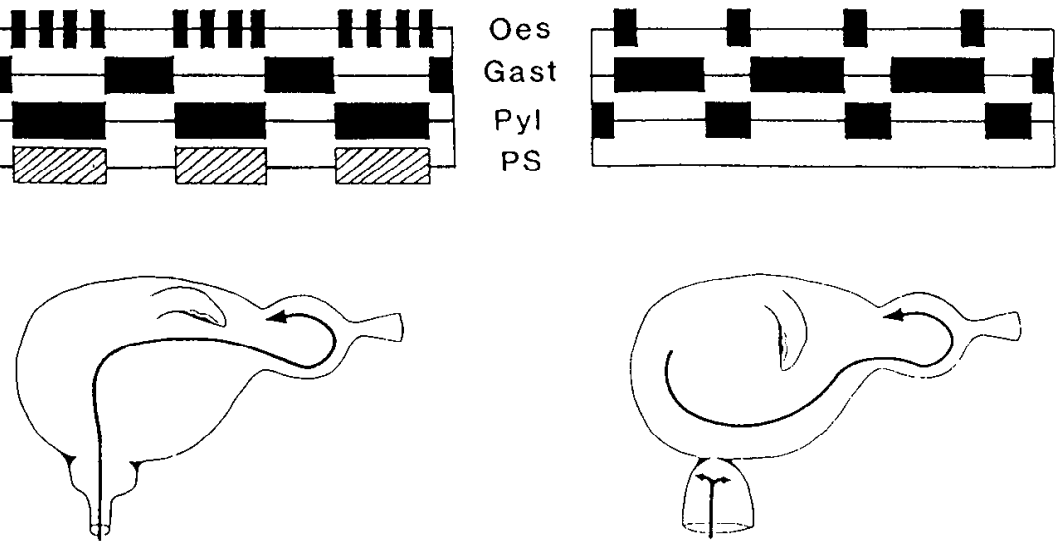

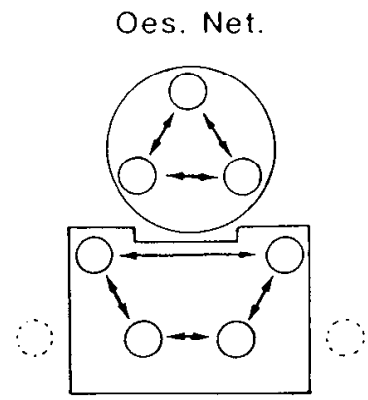

Gastro-pyloric Net.

Figure 12. Diagrammatic representation of the functional construction of the swallowing network by PS neurons from elements belonging to different STNS networks. $A$, When PS is silent, the esophageal, gastric, and pyloric networks (top) generate independent rhythmic output patterns (middle) involved in regionally specific and separate behavioral tasks (bottom). $B$, When PS is rhythmically active, it drives opening of the OCS valve (bottom), and by breaking down preexisting STNS networks and using certain neurons, it constructs a single novel network (top) that generates a coordinated motor pattern (middle) appropriate for swallowing behavior. $C$, When PS is again silent, the OSC valve closes (bottom) and motor units rostral to the OCS valve (i.e., esophageal elements) immediately resume their original network activity while units (i.e., gastric and pyloric) controlling regions more caudal to the sphincter continue to generate a single pattern before resuming their separate activities.

tegral members of these central circuits. Thus, the output pattern of an identified motor neuron provides an accurate indication both of the behavior for which it is responsible and the central activity that determines this output. To date the capacity of the STNS to generate swallowing-like behavior, in addition to the four regional motor tasks of the foregut, has not been described. This is perhaps not surprising since the underlying circuits preferentially and spontaneously express their separate region-specific patterns in vitro. Thus, given the rarity with which the PS neurons are themselves spontaneously active in isolated preparations, evidence that under certain circumstances these networks can be reconstituted into an entirely different functional network has failed to arise.

While a detailed analysis of the mechanisms involved in this dynamic reconfiguration of multiple STNS output by PS is outside the scope of the present report (Simmers et al., 1991; J. Simmers, P. Meyrand, and M. Moulins, unpublished observations), several major features are noteworthy here. First, PS is able to dismantle preexisting target circuits because it can alter, in a long-lasting fashion, the expression of intrinsic properties of many individual STNS neurons. For example, a previous study (Cazalets et al., 1990h; see Fig. 8) has shown that for certain neurons, such as the lateral pyloric neuron LP, the interneuron is able to inhibit their inherent plateauing properties in a manner that far outlasts (by several tens of seconds) the discharge of PS itself. The fact that LP switches from a plateauing to a "nonplateau" state has profound consequences for the functional integrity of the pyloric network as a whole. When LP is no longer in a bistable state, (1) it is unable to respond to phasic inputs from the other neurons within its own network and the cell remains silent, and (2) these pyloric partners, which are normally strongly influenced by synaptic input from LP, are now free to have their activity shaped by direct input from PS. For other stomatogastric neurons, PS enhances or activates intrinsic burst-generating properties (Cazalets et al., 1990b; Simmers et al., 1991), again leading to PS-timed modifications in output of the networks to which these cells belong. Second, via fast conventional postsynaptic actions (excitatory or inhibitory) that it exerts on a further subpopulation of stomatogastric neurons (see Fig. 2D-F; Cazalets et al., 1990a,b; Meyrand et al., 
1991; Simmers et al., 1991), PS is able to drive these diverse elements in phase (e.g., VD in Figs. 6, 8) or out of phase (e.g., LG in Fig. 6) with its own activity pattern. Third, the rhythmic activity of the swallowing pattern is generated by the PS neurons themselves (Fig. 7). These neurons appear to be endogenous bursters, expressing properties that characterize endogenous oscillators in general (Pinsker, 1977; Meyrand and Moulins, 1986). (1) The PS neurons can oscillate and produce bursts without evident synaptic potentials or after isolation from regions of possible synaptic input (data not shown), (2) they become rhythmically active in a voltage-dependent manner in response to direct tonic depolarization (Fig. 4B), and (3) the phase of the rhythm cycle can be reset by brief experimental perturbations (Fig. $4 C$ ). Thus, the ability of PS to reconfigure already operating STNS networks into a single new functional network appears to reside in the diversity of its synaptic influences acting in combination with the cell's own intrinsic membrane properties.

\section{Comparative aspects of network reconfiguration}

In a wider context, our data begin to challenge the concept of neuronal circuits as discrete predefined assemblages within the CNS, since they show that a network required for a complete behavioral task can be built up entirely from a pool of neurons already participating in other different behaviors. In other words a functional network can be seen as a strictly labile entity that according to modulatory influences may exist only to satisfy the demands of a particular behavioral situation.

Although it is now well established from invertebrates (Getting, 1989; Satterlie, 1989; Harris-Warrick and Marder, 1991) and vertebrates (Grillner et al., 1991) alike that a single anatomically defined network can produce different forms of the same behavior due to modulatory instruction, it has only recently emerged that the actual composition of a network is a plastic phenomenon with neurons being able to participate in more than one circuit and hence more than one behavior. To date the cellular basis of such network plasticity has been most extensively revealed in the crustacean STNS. In spiny lobsters, for example, a single neuron can switch from one pattern generator to another in response either to the activation of a sensory input pathway (Hooper and Moulins, 1989) or to exogenous peptidergic stimulation (Dickinson and Marder, 1989). In the crab Cancer borealis, neurons of both the pyloric or gastric CPGs can fire in time with either network (Weimann et al., 1991), while in Panulirus interruptus, bath application of the neuropeptide red pigment-concentrating hormone (RPCH) can fuse two independent rhythmic networks to form a novel conjoint rhythm (Dickinson et al., 1990). In these cases the cellular mechanisms underlying such alterations in network integrity appear to be the same as for modulation within a single network, that is, via alterations in the intrinsic firing properties of component ncurons (Hooper and Moulins, 1989) or changes in strength of synaptic connections between networks that otherwise function independently (Dickinson et al,, 1990). Our results add a significant new dimension to this theme in that rather than a switch of individual neurons between different ongoing rhythms or a functional merger of whole active circuits, we find that via their endogenous properties and multiaction postsynaptic effects (Cazalets et al., 1990b; Simmers et al., 1991; Simmers, Meyrand, and Moulins, unpublished observations), a single pair of interneurons can selectively dismantle several independently operating networks and construct a new network that bears no structural or functional resemblance to the circuits of origin (see Fig. 12).
This dynamic construction of a neural network also differs fundamentally from the "polymorphism" (Getting, 1989) seen in other motor pattern-generating systems. In the sea slug Tritonia, for example, the same interneuronal network that generates escape swimming (Getting, 1981, 1983) is also involved in reflex withdrawals under certain conditions (Getting and Dekin, 1985). However, here the switch from one behavior to the other does not require the dissolution of one network to create another, but rather, relies on the functional assimilation of different subsets of neurons into the same basic circuit. In the pteropod mollusk Clione limacina, the central network for swimming can be rewired to produce two distinct motor patterns underlying "weak" and "intense" locomotor behavior (Arshavsky et al., 1985a,b, Satterlie, 1989). Here again, the reconfiguration of the swim network is due to the active participation of an identified interneuron that remains silent during "weak" swimming (Arshavsky et al., 1985b). Thus, in both these systems and unlike the situation reported here, the switch from one functional network to another depends on the simple annexation of different elements to a parent circuit that otherwise maintains its structural and operational integrity.

In vertebrates, apparently straightforward behaviors such as walking and swimming may involve hundreds of different muscles that must be coordinated to produce meaningful behavior. In the lamprey, for example, undulatory swimming movements are coordinated by a chain of segmental pattern-generating networks (Grillner et al., 1991) that can reverse their phase coupling to produce spinal output appropriate for either forward or backward locomotion (Grillner and Matsushima, 1991). In cats, moreover, certain respiratory neurons can be involved in the control of vomiting (Miller et al., 1987, 1990), coughing and sneezing (Jakus et al., 1985). Here again, although these cases illustrate that entire unit networks or subsets of these circuits can be recombined to produce different motor acts, they still fall short of the restructuring capability describcd in the present report, namely, that according to a particular behavioral requirement, the nervous system is able dynamically to specify a completely new functional network from individual neurons of disparate origin.

\section{References}

Arshavsky YI, Beloozerova IN, Orlovsky GN, Panchin YV, Pavlova GA (1985a) Control of locomotion in marine mollusc Clione limacina. III. On the origin of locomotory rhythm. Exp Brain Res 58: 273-284.

Arshavsky YI, Bcloozcrova IN, Orlovsky GN, Panchin YV, Pavlova GA (1985b) Control of locomotion in marine mollusc Clione limacina. IV. Role of type 12 interneurons. Exp Brain Res 58:285293.

Bekoff A, Nusbaum MP, Sabichi AL, Clifford M (1987) Neuronal control of limb coordination. I. Comparison of hatching and walking motor output patterns in normal and deafferented chicks. J Neurosci 7:2320-2330.

Cazalets JR, Nagy F, Moulins M (1990a) Suppressive control of the crustacean pyloric network by a pair of identified interneurons. I. Modulation of the motor pattern. J Neurosci 10:448-457.

Cazalets JR, Nagy F, Moulins M (1990b) Suppressive control of the crustacean pyloric network by a pair of identified interneurons. II. Modulation of neuronal properties. J Neurosci 10:458-468.

Dclancy K, Gelpcrin A (1990a) Ccrebral interneurons controlling fictive feeding in Limax maximus. II. Initiation and modulation of fictive feeding. J Comp Physiol [A] 166:311-326.

Delaney K, Gelperin A (1990b) Cerebral interneurons controlling fictive feeding in Limax maximus. III. Integration of sensory inputs. J Comp Physiol [A] 166:327-343. 
Delcomyn F (1980) Neural basis of rhythmic behavior in animals. Science 210:492-498.

Dickinson PS, Marder E (1989) Peptidergique modulation of a multioscillator system in the lobster. I. Activation of the cardiac sac motor pattern by the neuropeptides proctolin and red pigment-concentrating hormone. J Neurophysiol 61:833-844.

Dickinson PS, Mecsas C, Marder E (1990) Neuropeptide fusion of two motor-pattern generator circuits. Nature 344:155-158.

Getting PA (1981) Mechanisms of pattern generation underlying swimming in Tritonia. I. Neuronal network formed by monosynaptic connections. J Neurophysiol 46:65-79.

Getting PA (1983) Mechanisms of pattern generation underlying swimming in Tritonia. III. Intrinsic and synaptic mechanisms for delayed excitation. J Neurophysiol 49:1036-1050.

Getting PA (1989) Emerging principles governing the operation of neuronal networks. Annu Rev Neurosci 12:185-204.

Getting PA, Dekin MS (1985) Tritonia swimming: a model system for integration within rhythmic motor systems. In: Model networks and behavior (Selverston AI, ed), pp 3-20. New York: Plenum.

Gillette R, Kovac MP, Davis WI (1982) Control of feeding motor output by paracerebral neurons in the brain of Pleurobranchaea californica. J Neurophysiol 47:885-908.

Grillner S (1981) Control of locomotion in bipeds, tetrapods and fish. In: Handbook of physiology, Sec 1, The nervous system, Vol II, Pt 2 (Books VB, ed), pp 1179-1236. Bethesda: American Physiological Society.

Grillner S (1985) Neurobiological bases of rhythmic motor acts in vertebrates. Science. 228:143-149.

Grillner S (1991) Recombination of motor pattern generators. Curr Opinion Biol 1:231-233.

Grillner S, Matsushima T (1991) The neural network underlying locomotion in lamprey, synaptic and cellular mechanisms. Neuron $7: 1-$ 15.

Grillner S, Wallen P, Brodin L, Lansner A (1991) Neuronal network generating locomotor behavior in lamprey: circuitry, transmitters, membrane properties, and simulation. Annu Rev Neurosci 14:169199.

Harris-Warrick RM, Marder E (1991) Modulation of neural networks for behavior. Annu Rev Neurosci 14:39-57.

Harris-Warrick RM, Nagy F, Nusbaum MP (1992) Neuromodulation of stomatogastric networks by identified neurons and transmitters. In: Dynamic biological networks: the stomatogastric nervous system (Harris-Warrick RM, Marder E, Selverston AI, Moulins M, eds), pp 87-138. Boston: MIT Press.

Heinzel HG (1988) Gastric mill activity in the lobster. I. Spontaneous modes of chewing. J Neurophysiol 59:528-549.

Hooper SL, Moulins M (1989) A neuron switches from one network to another by sensory induced changes in its membrane properties. Science 244:1587-1589.

Jakus J, Tomori Z, Stransky A (1985) Activity of bulbar respiratory neurons during cough and other respiratory tract reflexes in cats. Physiol Bohemoslov 34:127-136.

Jean A, Car A (1979) Inputs to the swallowing medullary neurons from the pcripheral afferent fibers and the swallowing cortical area. Brain Res 178:567-572.

Katz PS, Harris-Warrick RM (1991) Actions of identified neurmodulatory neurons in a simple motor system. Trends Neurosci 13:367373.

Kemenes G, Elliott CJH, Benjamin PR (1986) Chemical and tactile inputs to the Lymnaea feeding system: effects on behaviour and neural circuitry. J Exp Biol 122:113-138.

Marder E (1987) Neurotransmitters and neuromodulators. In: The stomatogastric nervous system (Selverston AI, Moulins M, eds), pp 263-300. New York: Springer.
Maynard DM (1972) Simpler networks. Ann NY Acad Sci 193:5972 .

Maynard DM, Dando MR (1974) The structure of the stomatogastric neuromuscular system in Callinectes sapidus, Homarus gammarus and Panulirus argus. Philos Trans R Soc Lond [Biol] 268:161-220.

Meyrand P, Moulins M (1986) Myogenic oscillatory activity in the pyloric rhythmic motor system of Crustacea. J Comp Physiol [A] 158 : 489-503.

Meyrand P, Simmers J, Moulins M (1991) Construction of a patterngenerating circuit with neurons of different networks. Nature 351:6063

Miller AD, Tan LK, Suzuki I (1987) Control of abdominal and expiratory intercostal muscle activity during vomiting: role of ventral respiratory group expiratory neurons. J Neurophysiol 57:1854-1866.

Miller AD, Nonaka S, Lakos SF, Tan LK (1990) Diaphragmatic and external intercostal muscle control during vomiting: behavior of inspiratory bulbospinal neurons. J Neurophysiol 63:31-36.

Miller AJ (1982) Deglutition. Physiol Rev 62:129-184.

Miller JP (1987) Pyloric mechanisms. In: The stomatogastric nervous system (Selverston AI, Moulins M, eds), pp 109-145. New York: Springer.

Moulins M, Vedel JP (1977) Programmation centrale de l'activité motrice rythmique du tube digestif antérieur chez les crustacés décapodes. J Physiol (Paris) 73:471-510.

Pinsker HR (1977) Aplysia bursting neurons as endogenous oscillators. II. Synchronization and entrainment by pulsed inhibitory synaptic input. J Neurophysiol 40:544-556.

Rezer E, Moulins M (1983) Expression of the crustacean pyloric pattern generator in the intact animal. J Comp Physiol 153:17-28.

Robertson RM, Laverack MS (1979) Oesophageal sensors and their modulatory influence on oesophageal peristalsis in the lobster, $\mathrm{Hom}$ arus gammarus. Proc R Soc Lond [Biol] 206:235-263.

Rose RM, Benjamin PR (1981a) Interneuronal control of feeding in the pond snail Lymnaea stagnalis. I. Initiation of feeding cycles by a single buccal interneuron. J Exp Biol 92:187-201.

Rose RM, Benjamin PR (1981b) Interneuronal control of feeding in the pond snail Lymnaca stagnalis. II. The interneuronal mechanisms generating feeding cycles. J Exp Biol 92:203-228.

Rosen SC, Teyke T, Miller MW, Weiss KR, Kupfermann I (1991) Identification and characterization of cerebral-to-buccal interneurons implicated in the control of motor programs associated with feeding in Aplysia. $\mathbf{J}$ Neurosci 11:3630-3655.

Satterlie RA (1989) Reciprocal inhibition and rhythmicity: swimming in a Pteropod mollusk. In: Neuronal and cellular oscillators (Jacklet JW, ed), pp 151-171. New York: Dekker.

Selverston AI, Moulins M (1987) The crustacean stomatogastric system. A model for the study of central nervous systems. Berlin: Springer.

Simmers AJ, Moulins M (1988) A disynaptic sensori-motor pathway in the lobster stomatogastric system. J Neurophysiol 59:740-756

Simmers AJ, Meyrand P, Moulins M (1991) Mechanisms subserving construction of a novel motor-pattern generating network by a multiaction interneuron. Soc Neurosci Abstr 17:1489.

Spirito CP (1975) Organization of the crayfish oesophageal nervous system. J Comp Physiol 102:237-249.

Vedel JP, Moulins M (1977) Functional properties of interganglionic motor neurons in the stomatogastric nervous system of the rock lobster. J Comp Physiol 118:307-325.

Weimann JM, Meyrand P, Marder E (1991) Neurons that form multiple pattern generators: identification and multiple activity patterns of gastro/pyloric neurons in the crab stomatogastric system. J Neurophysiol 65:111-122. 